\title{
In the Path of the Storm: Does Distress Risk Cause Industrial Firms To Risk-Shift?*
}

\author{
Kevin Aretz \\ Manchester Business School \\ kevin.aretz@mbs.ac.uk
}

\author{
Shantanu Banerjee \\ Lancaster University \\ s.banerjee@lancs.ac.uk
}

\author{
Oksana Pryshchepa \\ University of Birmingham \\ o.pryshchepa@bham.ac.uk
}

This Draft: July 15, 2018

\begin{abstract}
We study whether industrial firms risk-shift in response to distress risk increases induced through hurricane strikes. Using new proxies capturing deliberate managerial decisions about the risk of a firm's operating segment portfolio, differences tests suggest that hurricane strikes prompt moderately, but not highly, distressed firms to skew their asset mixes towards riskier segments by shutting down low-risk, high-average-Q segments. In turn, the moderately distressed firms observe abnormally high failure rates after a hurricane strike. Employing covenant violation data, we offer further evidence that creditor control prevents highly distressed firms from raising their risk. Our conclusions extend those of other studies by suggesting that moderate distress risk levels can lead the managers of industrial firms to not only engage in risk-taking, but, in fact, in risk-shifting.
\end{abstract}

Key words: Agency conflicts; risk-shifting; distress risk; segment data; hurricane strikes.

JEL classification: G32, G33.

\footnotetext{
*Corresponding author: Shantanu Banerjee, Department of Accounting and Finance, Lancaster University Management School, Bailrigg, Lancaster, LA1 4YX, United Kingdom, tel.: +44(0)1524 593 200. We are indebted to an anonymous referee and the managing editor (Andrew Ellul) for detailed, insightful, and constructive advice. We are further indebted to Murillo Campello, Martin Conyon, Sudipto Dasgupta, Ran Duchin, Eric Gilje, Simi Kedia, Hamed Mahmudi, Maria-Teresa Marchica, Bang Nguyen, Ingmar Nolte, Ken Peasnell, Florian Peters, Tavy Ronen, Pedro Saffi, Enrique Schroth, Mark Shackleton, Kostas Stathopoulos, Jérôme Taillard, Grzegorz Trojanowski, Francesco Vallascas, conference participants at the 2013 Paris Financial Management Conference, the 2014 European Finance Association Meeting, the 2014 Financial Management Association European Conference, the 2015 Edinburgh Corporate Finance Conference, the 2015 European Financial Management Association Meeting, the 2017 Financial Intermediation Research Society (FIRS) Conference, and seminar participants at Exeter University, Glasgow University, Lancaster University, the University of Paris-Dauphine, and Trier University for many helpful comments and suggestions.
} 


\title{
In the Path of the Storm: Does Distress Risk Cause Industrial Firms To Risk-Shift?
}

\author{
This Draft: July 15, 2018
}

\begin{abstract}
We study whether industrial firms risk-shift in response to distress risk increases induced through hurricane strikes. Using new proxies capturing deliberate managerial decisions about the risk of a firm's operating segment portfolio, differences tests suggest that hurricane strikes prompt moderately, but not highly, distressed firms to skew their asset mixes towards riskier segments by shutting down low-risk, high-average-Q segments. In turn, the moderately distressed firms observe abnormally high failure rates after a hurricane strike. Employing covenant violation data, we offer further evidence that creditor control prevents highly distressed firms from raising their risk. Our conclusions extend those of other studies by suggesting that moderate distress risk levels can lead the managers of industrial firms to not only engage in risk-taking, but, in fact, in risk-shifting.
\end{abstract}

Key words: Agency conflicts; risk-shifting; distress risk; segment data; hurricane strikes.

JEL classification: G32, G33. 
"Aggressive game playing is done only by out-and-out crooks ... and by firms in extreme financial distress."

Brealey, Myers, and Allen (2014), p.464.

\section{Introduction}

In a seminal paper, Jensen and Meckling (1976) hypothesize that managers acting in shareholders' best interest have an incentive to substitute safer for riskier assets, with the incentive being stronger in high distress-risk situations (see also Black and Scholes, 1973). However, despite this "risk-shifting" hypothesis being well-known and thoroughly theoretically developed, ${ }^{1}$ it has remained elusive to find empirical evidence suggesting that the managers of industrial firms risk-shift. Only very recently, a small number of studies, including Becker and Strömberg (2012), Gilje (2016), and Favara et al. (2017), have made steps into this direction. While these studies show that high distress risk sometimes causes the managers of industrial firms to take on more risk, they offer only limited evidence on whether this behavior hurts creditors. Thus, while their evidence suggests risk-taking, it does not necessarily imply risk-shifting.

In our paper, we offer evidence that the managers of some industrial firms not only raise their firms' risk, but also hurt their creditors in response to exogenous distress risk increases, suggesting that these managers risk-shift. To do so, we assume that a firm can be viewed as a portfolio of operating segments, with managers deliberately altering the portfolio through their expansion and contraction decisions. To estimate the risk of this portfolio, we use Markowitz's (1952) portfolio variance formula, calculating the weights in that formula using either the book values (yielding a proxy for total firm risk) or the capital expenditures of the operating segments (yielding a proxy for the risk of the new real-assets invested into over a year). We next calculate

\footnotetext{
${ }^{1}$ See, for example, Smith and Warner (1979), Gavish and Kalay (1983), Green (1984), Green and Talmor (1986), Campbell and Kracaw (1990), Leland (1998), and Chen et al. (2014).
} 
the variance-covariance terms in the formula using the returns of pure-play firm industry portfolios containing only firms exclusively operating in the segments' industries. Assuming that managers are more able to change the weights than the variance-covariance terms, we keep the variance-covariance terms constant in all our calculations, ensuring that variations in the risk proxies reflect deliberate managerial decisions about firm risk. To also make inferences about investment efficiency, we follow Shin and Stulz (1998) and Dittmar and Shivdasani (2003) and calculate each segment's average-Q as the average of the market-to-book ratio taken over all pure-play firms exclusively operating in a segment's industry.

To study the causal effects of distress risk on our analysis variables, we use hurricane strikes as exogenous shock to distress risk, relying on two identification contrasts in a triple differences ("DIDID") setup. Hurricane strikes fulfill most conditions to be a valid instrument for distress risk. In particular, (i) most firms are exposed to them (Dailey et al., 2009); (ii) their incidences and paths are almost impossible to predict (Emanuel and Zhang, 2016); and (iii) they cause severe economic damages. Also, while the public and private sector offer insurance against losses arising from hurricane strikes, only about half of all firms with a significant exposure to hurricane strikes take out such policies (Henry et al., 2013). In accordance, the Insurance Information Institute ("iii") reports that insured hurricane losses make up slightly less than half of overall hurricane losses over the 1980-2015 period. ${ }^{2,3}$ Thus, our first identification contrast is between hurricane-struck firms and non-hurricane-struck firms.

\footnotetext{
${ }^{2}$ See the figure titled "Tropical Storms and Hurricanes in the North Atlantic, 1980-2015," available from the URL address: <https://www.iii.org/fact-statistic/facts-statistics-us-catastrophes>.

${ }^{3}$ It is well known that economic agents tend to underinsure against catastrophes. For example, O'Doherty and Smith (1993) offer case-study evidence that British Petroleum self-insures against catastrophes. Froot (2001) shows that reinsurance firms tend to insure less than 30\% of their catastrophic losses. Garmaise and Moskowitz (2009) report that only about 35\% of properties located in areas prone to earthquakes take out earthquake insurance. The dominant view is that the low catastrophe insurance rates are the result of excessively high catastrophe insurance premia, possibly driven by a limited supply of insurance capital and the market power of the few firms able to offer insurance against catastrophes (see Froot, 2001).
} 
One condition for valid instruments that is, however, likely to be violated by hurricane strikes is that they must affect our analysis variables only through increasing distress risk, and not through other channels. This condition would, for example, be violated if hurricane strikes also affected a firm's future prospects or labor relations, leading managers to readjust their firms' asset mixes for non-distress-risk reasons. To mitigate confounding effects arising through other channels, we use a second identification contrast between pre-hurricane-strike healthy and distressed firms. Given that theory suggests that healthy firms have (almost) no incentive to risk-shift, this second contrast should difference out effects other than distress risk. While we acknowledge that healthy and distressed firms differ in absolute terms, parallel trends tests suggest they observe similar changes in key variables over the pre-hurricane-strike period. More importantly, we also repeat our tests on a matched sample, ensuring that the healthy and distressed firms have a similar size, age, asset tangibility, and industry composition.

Our evidence suggests that hurricane strikes induce the managers of moderately distressed ("ailing") firms to skew their firms' asset mixes towards higher-risk segments. In contrast, if anything, they induce the managers of highly distressed ("distressed") firms to skew their firms' asset mixes towards lower-risk segments. Our univariate analysis, for example, suggests that, while the ailing firms significantly increase the risks of their operating segment portfolio ("firm risk") and new real-assets portfolio ("investment risk") by about 1.2 percentage points in response to a hurricane strike, the distressed firms insignificantly decrease theirs by 0.3 and 0.1 points, respectively. ${ }^{4}$ In comparison, healthy non-hurricane-struck firms observe increases of about 0.2 points over matched periods. While the increases in risk observed by the ailing hurricane-struck firms may appear economically low, our risk proxies are far less volatile than, for example, the volatilities of real stock-portfolios. Thus, contrary to appearances, the increases in the risk proxies are actually above the 90th percentiles of the full-sample distributions of

\footnotetext{
${ }^{4}$ While the decreases in risk observed by the distressed firms are insignificant in our univariate analysis, they sometimes become significant in our regression analysis including control variables.
} 
changes in the risk proxies, suggesting that they are economically meaningful.

Further tests reveal that the risk changes of the ailing and distressed firms are spurred by these firms restructuring themselves. The ailing firms, for example, tend to change their business orientation and close segments, with the probability of them changing their main segment rising by twelve percentage points and them closing one-fifth of a segment on average. Crucially, however, the ailing firms do not close segments to start hoarding (risk-free) cash. Further, they also do not become more likely to act as acquirer or target in a mergers and acquisitions (M\&A) deal. In comparison, while the distressed firms also tend to change their business orientation, our evidence suggests that they do not change their number of segments. Overall, if the intention of the ailing hurricane-struck firms is to risk-shift, it is perhaps unsurprising that they do so through closing segments, since it is probably faster to close than to open a segment and the firms probably face some urgency to act. More surprising, however, is that the risk-shifting would not be facilitated through M\&A activity, suggesting it is not always possible to use M\&A activity to study risk-shifting (e.g., Acharya, Amihud, and Litov, 2011).

Our evidence so far suggests that the managers of ailing firms raise their firms' risk after a hurricane strike. This behavior would, however, only translate into risk-shifting if it hurt creditors. To establish that it does, we first show that the higher risk of the ailing hurricanestruck firms is the result of poor investments into segments with low growth opportunities (low average-Qs), while the lower risk of the distressed hurricane-struck firms is the result of good investments into segments with high growth opportunities (high average-Qs). For example, while the average-Q of the ailing firms' new real-assets portfolio significantly decreases by 0.33 after a hurricane strike, the average-Q of the distressed firms' new real-assets portfolio significantly increases by 0.34 . We next show that the risk-taking behavior of the ailing firms significantly raises their chance to fail over the next ten years, with them being six percentage points more likely to fail over that period than the distressed hurricane-struck firms. In contrast, ailing non-hurricane-struck firms are ten percentage points less likely to fail than distressed 
non-hurricane-struck firms over matched periods. Both the poor investment decisions and the abnormally high failure risk of the ailing firms lower the chance that these firms are able to fully repay their creditors in the future. Thus, they hurt the firms' creditors.

One final piece of evidence suggesting that the ailing firms do not act in creditors' best interest can be deduced from studying why the ailing and distressed firms respond so differently to hurricane strikes. In a seminal paper, Chava and Roberts (2008) show that creditors restrict managerial decision-making in firms violating financial covenants. In accordance, Gilje (2016) shows that creditor control facilitated through covenant violations explains why oil and gas firms reduce risk in response to exogenous increases in distress risk. Thus, if our ailing firms were significantly less likely to be under creditor control than our distressed firms, creditor control may explain the different reactions of the two types of firms. To verify this hypothesis, we first show that covenant violations are far less common among ailing than distressed firms. More importantly, however, we also split the sample of ailing firms into covenant compliers and covenant violators. We then offer evidence that, while the compliers raise their risk when hit by a hurricane, the violaters lower theirs. Given that the subsample of violators reveals creditors' preferred response to hurricane-strike-induced distress risk increases, it follows that the risktaking of the ailing compliers must be suboptimal from creditors' perspective.

Our work contributes to the empirical risk-shifting literature. While a large number of studies suggest that distress risk prompts financial firms to risk-shift, ${ }^{5}$ the evidence on whether distress risk prompts industrial firms to do the same is more sparse. In the early literature on

\footnotetext{
${ }^{5}$ Saunders, Strock, and Travlos (1990) and Laeven and Levine (2009) show that financial deregulation raises the volatilities, market betas, and distress risk of stockholder-controlled banks. Esty (1997a) shows that savings and loan associations increased their asset risk in the 1980s and 1990s. Esty (1997b) offers case study evidence corroborating these results. Relying on fund volatilities and tracking errors, Brown, Harlow, and Starks (1996), Brown, Goetzmann, and Park (2001), and Basak, Pavlova, and Shapiro (2007) show that poor performance leads mutual funds and hedge funds to risk-shift. Using an asset-holding based proxy, Huang, Clemens, and Hanjiang (2011) offer further evidence that mutual funds risk-shift.
} 
industrial firms, Andrade and Kaplan (1998) find no evidence that firms ending up in distress after leveraged re-capitalizations take on more risk. Surveying U.S. and Dutch chief financial officers (CFOs), Graham and Harvey (2001) and DeJong and VanDijk (2007) find that the CFOs attach little importance to risk-shifting. Using structural-model implied asset volatilities to proxy for firm risk, Fang and Zhong (2004) and Larsen (2006) obtain the surprising finding that risk-taking is U-shaped in distress risk. Conversely, Eisdorfer (2008) offers theoretical evidence that the incentive to risk-shift induces distressed, but not healthy, firms to speed up investments in response to an increase in uncertainty. In accordance, he finds that regressions of firm-level investment on aggregate volatility produce a negative relation for healthy firms, but a positive relation for distressed firms. Extending his research, Pryshchepa, Aretz, and Banerjee (2013) show that it is the distressed firms that are not yet identified as distressed (e.g., those still in compliance with their covenants) that produce the positive relation.

Closer to our work, recent studies use exogenous shocks to study whether distress risk leads industrial firms to take on more risk. Becker and Strömberg (2012) study a legal change in U.S. fiduciary duties forcing managers to keep creditors' interests in mind in high distress-risk situations. They find that the change decreases the equity- and return-on-assets-volatilities of distressed, but surprisingly also healthy, firms. Similarly, Favara et al. (2017) show that bankruptcy reforms reducing the incentive to risk-shift lead to decreases in the equity volatilities of distressed firms relative to healthy firms. Given that these studies offer only limited evidence suggesting that the risk-taking found by them reduces firm value and thus amounts to riskshifting ${ }^{6}$ we contribute to them by showing that the risk-taking found by us is attributable to value-reducing managerial decisions. Using the ratio of high risk ("exploratory") projects to

\footnotetext{
${ }^{6}$ Becker and Strömberg (2012) show that the equity values of firms with low to moderate leverage ratios increase, while those of firms with high leverage ratios decrease, in response to the change in fiduciary duties, which is consistent with risk-shifting. The decreases in the equity values of the firms with high leverage ratios are, however, insignificant, so that we can draw only limited inferences from them. Favara et al. (2017) do not study the value consequences of the risk-taking behavior documented by them.
} 
low risk ("developmental") projects to proxy for the risk of oil and gas firms, Gilje (2016) shows that exogenous shocks to financial leverage induce these firms to take on less risk, with the decrease in risk being especially pronounced for covenant violators. We complement his results by showing that, while covenant violators may not be able to raise their risk in response to distress risk increases, covenant compliers are able to do so, at least in our setting.

Our paper is organized as follows. Section 2 discusses our analysis variables. In Section 3, we describe our methodology. Section 4 outlines our data sources. Section 5 offers our empirical results. Section 6 reports the results from robustness tests. Section 7 concludes.

\section{Analysis Variables}

In this section, we introduce our analysis variables. We first describe how we estimate the risks of a firm's operating segment portfolio and its new real-assets portfolio. We next explain how we extract a firm's distress risk from Merton's (1974) model. We finally describe the calculations of other variables. See Table A.1 in the Appendix for more details about the variables.

\subsection{Firm Risk and Investment Risk}

We interpret a firm as a portfolio of operating segments, motivating us to calculate the total risk of the firm and the risk of the new real-assets added to the firm using Markowitz's (1952) portfolio variance formula. Let $A_{i_{s}, t}$ be the value of segment $s$ of firm $i$ at the end of fiscal year $t, A_{i, t}$ the sum over the values of all segments, and $S_{i, t}$ the number of segments. Denoting by $t^{*}$ a higher-frequency time index than $t$, let $r_{s, t^{*}}$ be the period $t^{*}$ return of segment $s$. We define the return of a portfolio mimicking the return of firm $i$ over period $t^{*}, r_{i, t^{*}}^{A}$, as:

$$
r_{i, t^{*}}^{A}=\sum_{s=1}^{S_{i, t}} \frac{A_{i_{s}, t}}{A_{i, t}} r_{s, t^{*}} .
$$


Similarly, let $C_{i_{s}, t}$ be the investments made into segment $s$ of firm $i$ over fiscal year $t$ and $C_{i, t}$ the sum over all segment investments. We define the return of a portfolio mimicking the return of the new real-assets invested into by firm $i$ over period $t^{*}, r_{i, t^{*}}^{C}$, as:

$$
r_{i, t^{*}}^{C}=\sum_{s=1}^{S_{i, t}} \frac{C_{i_{s}, t}}{C_{i, t}} r_{s, t^{*}}
$$

We next compute the total risk of firm $i$ at the end of fiscal year $t$, FirmRisk, as the standard deviation of $r_{i, t^{*}}^{A}, \sigma\left(r_{i, t^{*}}^{A}\right)$, and the risk of the new real-assets invested into by the firm over that fiscal year, InvestmentRisk, as the standard deviation of $r_{i, t^{*}}^{C}, \sigma\left(r_{i, t^{*}}^{C}\right)$, where both standard deviations are annualized and stated in percent. Markowitz (1952) suggests that either standard deviation can be written as as a function of variances and covariances:

$$
\sigma\left(r_{i, t^{*}}^{w}\right)=\left(\sum_{s=1}^{S_{i, t}}\left(\frac{w_{i_{s}, t}}{w_{i, t}}\right)^{2} \sigma\left(r_{s, t^{*}}\right)^{2}+\sum_{s=1}^{S_{i, t}} \sum_{n \neq s}^{S_{i, t}} \frac{w_{i_{s}, t}}{w_{i, t}} \frac{w_{i_{n}, t}}{w_{i, t}} \sigma\left(r_{s, t^{*}}, r_{n, t^{*}}\right)\right)^{\frac{1}{2}}
$$

where $w \in\{A, C\}, \sigma\left(r_{s, t^{*}}\right)^{2}$ is the return variance of segment $s$, and $\sigma\left(r_{s, t^{*}}, r_{n, t^{*}}\right)$ is the return covariance between segments $s$ and $n$. Equation (3) shows that FirmRisk and InvestmentRisk reflect both the volatilities of the segments in a firm's segment portfolio (through the variance terms), but also the co-movements between the segments (through the covariance terms).

We use a segment's book value of assets to measure its value $\left(A_{i_{s}, t}\right)$ and its capital expenditures to measure investments into the segment $\left(C_{i_{s}, t}\right)$. We calculate the variances and covariances of the segments by forming stock portfolios containing only firms exclusively operating in one single industry ("pure-play firm industry portfolios"). To this end, we first sort firms exclusively operating in one four-digit SIC industry into four-digit SIC industry portfolios, requiring that each portfolio contains a minimum of three firms over the entire sample period. Using the firms from the sample of industry portfolios violating this restriction, we sort them into three-digit SIC industry portfolios, again imposing the restriction that the 
portfolios contain a minimum of three firms. We proceed in this way until we reach one-digit SIC industry portfolios. ${ }^{7}$ We calculate value-weighted weekly stock returns for each portfolio, measuring weekly returns from end of Wednesday of the previous week to end of Wednesday of the current week. ${ }^{8}$ We finally calculate the (time-invariant) variances and covariances of the pure-play firm industry portfolios using data over the January 1977-December 2011 period and merge the estimates with the segments based on the segment SIC codes. ${ }^{9}$

On an intuitive level, a firm's variations in FirmRisk and InvestmentRisk reflect how the volatilities of the firm's operating segment portfolio and its new real-assets portfolio evolve over time. However, because we only allow the segment, but not the pure play firm industry portfolio, data to change over time, the variations in the risk proxies are entirely attributable to variations in the segment weights, and not to variations in the variances and covariances of the segments. Only allowing the segment, but not the industry portfolio, data to change over time is consistent with our view that, while managers are able to allocate resources across segments, they are unlikely to be able to greatly alter the risks of the segments.

FirmRisk is related to other risk proxies used in the literature. In particular, we can view the firm-level change in FirmRisk as a continuous version of Acharya, Amihud, and Litov's (2011) risk-taking proxy, a dummy variable equal to one for firms engaging in focusing mergers and

\footnotetext{
${ }^{7}$ About $77 \%$ of our firm-year observations end up within four-digit SIC industry portfolios, with the remainder ending up within either two- or three-digit portfolios.

${ }^{8}$ While asset returns better reflect asset risks, the number of unlevered stocks traded in the United States is too low to exclusively use unlevered stocks to form the industry portfolios. In a robustness test, we later, however, use stock returns delevered using the structural model of Merton (1974) to address the concern that cross-industry variations in financial leverage bias our empirical conclusions.

${ }^{9}$ Since volatility clusters over time, managers may base their investment decisions on more conditional estimates of the variances and covariances of the segments than those used in our main tests. In a previous version of our paper, we have thus studied changes in the risk proxies calculated using variances and covariances estimated over the twelve months of weekly returns prior to the end of fiscal year $t$. Despite higher estimation errors, we found results consistent with those reported in our paper.
} 
zero for firms engaging in diversifying mergers. Thus, their risk-taking proxy reflects the degree of co-movement between a firm's core assets and its newly acquired assets. While FirmRisk captures the same through the covariance terms in Equation (3), it also captures the absolute risks of a firm's assets through the variance terms in that equation, ensuring that, for example, a high-tech firm buying a utility firm would not be considered as risk-taking.

FirmRisk is also related to the risk proxies used by Huang, Clemens, and Hanjiang (2011) and Armstrong and Vashishtha (2012). The former authors estimate the risks of financial firms by calculating the volatilities of the financial investments made by them. Closer to us, the latter authors estimate the risks of industrial firms by calculating the volatilities of the operating segment portfolios owned by them. In contrast to us, Armstrong and Vashishtha (2012), however, allow for variations in their risk proxy attributable to both the segment weights, but also to the variances and covariances of the segments.

\subsection{Distress Risk}

We use the Merton (1974) model to estimate a firm's default probability over the twelve months after the end of month $t$. To this end, we follow Vassalou and Xing (2004) and use the Black and Scholes (1973) European call option valuation formula to calculate each firm's asset value, $A_{i, t}$, at the end of each trading day over the twelve months before the end of month $t$ :

$$
E_{i, t}=A_{i, t} N\left(d_{1 ; i, t}\right)-K_{i, t} e^{-r} N\left(d_{2 ; i, t}\right)
$$

where $E_{i, t}$ is the equity value, $K_{i, t}$ the sum of short-term debt and one-half times long-term debt, and $r$ the annualized risk-free rate of return. Moreover, $N($.$) is the cumulative standard$ normal density, $d_{1 ; i, t}$ is $\left(\ln \left(\frac{A_{i, t}}{K_{i, t}}\right)+\left(r+\frac{1}{2} \sigma_{i, t}^{2}\right)\right) / \sigma_{i, t}$, and $d_{2 ; i, t}$ is $d_{1 ; i, t}-\sigma_{i, t}$, where $\sigma_{i, t}$ is the annualized asset volatility. To obtain an estimate of asset volatility, we initially set asset volatility to an estimate of stock volatility calculated from daily data over the twelve-month 
period. Using the stock volatility estimate, we then calculate a time-series of daily asset values over that period. We finally reestimate asset volatility from the daily percent changes in the time-series of the asset values. Using the new asset volatility estimate, we repeat the above procedure, updating the asset volatility estimate until it converges. Upon convergence, we plug the most recent implied asset value, the most recent value for the sum of short-term debt and one-half times long-term debt, the annualized mean asset return, $\mu$, and the final asset volatility estimate into Merton's (1974) default probability formula:

$$
\text { DistressRisk }_{i, t}=N\left[-\frac{\ln \left(\frac{A_{i, t}}{K_{i, t}}\right)+\left(\mu-\frac{1}{2} \sigma_{i, t}^{2}\right)}{\sigma_{i, t}}\right] \text {. }
$$

\subsection{Other Variables}

We use Capex, Focus, NumberSegments, Cash, and AcquisitionExpense to examine how a firm changes the risks of its operating segment portfolio and new real-assets portfolio. Capex is capital expenditures scaled by total assets. Focus is a dummy variable equal to one if a firm's main operating segment, defined as the segment with the highest sales, changes its two-digit SIC industry code over the fiscal year, and else zero. NumberSegments is the number of operating segments owned by a firm. Cash is cash and cash equivalents scaled by total assets. AcquisitionExpense is acquisition expenditures scaled by total assets.

To study the real consequences of the changes in risk, we analyze whether the changes are facilitated through investments into segments with good or bad growth opportunities. To measure growth opportunities, we follow Shin and Stulz (1998), Dittmar and Shivdasani (2003), Datta, D’Mello, and Iskandar-Datta (2009), and Gopalan and Xie (2011). More specifically, we calculate a segment's average- $\mathrm{Q}$ as the value-weighted average of the ratio of total assets minus the book value of equity plus the market value of equity minus deferred taxes to total assets, taken over all pure play firms operating in the segment's industry (defined as described above). In turn, we calculate the aggregate average-Q of a firm as the value-weighted average 
of the average-Qs of the segments owned by the firm, using either the book value of assets, Average $Q^{\text {Firm }}$, or the capital expenditures, Average $Q^{\text {NewAssets }}$, of the segments to compute the weights. We also examine data on bankruptcy filings, distressed mergers (defined as mergers involving at least one firm with a top tercile DistressRisk value over the two years before the merger-related delisting), and performance-related exchange delistings.

We use Assets, PPEEE, and $P P \mathscr{E} E^{2}$ as control variables in our tests. Assets is the natural log of total assets, reported in 2010 dollars. PPEE is net property, plant, and equipment scaled by last fiscal year's total assets. In line with Himmelberg, Hubbard, and Palia (1999), we also use $P P \mathscr{E} E^{2}$, the square of $P P \mathscr{E} E$, to allow for non-linearities in the relation between firm risk and asset tangibility. In parallel trends tests, we further include BookToMarket, defined as the ratio of a firm's book value of equity to its stock market capitalization.

\section{The Causal Inference Tests}

In this section, we offer details about the differences methodology used in our paper. We start with explaining why hurricane strikes are likely to be a valid instrument for distress risk. We next describe the mean-comparison and regression tests used in our empirical work.

\subsection{Using Hurricane Strikes as Instrument for Distress Risk}

We use distress risk increases induced through hurricane strikes to establish whether distress risk induces industrial firms to skew their asset mixes towards riskier assets. A hurricane is a rapidly rotating storm system ("tropical cyclone") with sustained winds of at least 74 miles per hour. It usually has an area of low atmospheric pressure at its center. Hurricanes spawn in the North Atlantic or Pacific Ocean between the start of June and the end of November ("hurricane season"). For hurricane strikes to be a valid instrument for distress risk, they must fulfill four conditions. First, their effects must extend over a large number of U.S. areas, ruling 

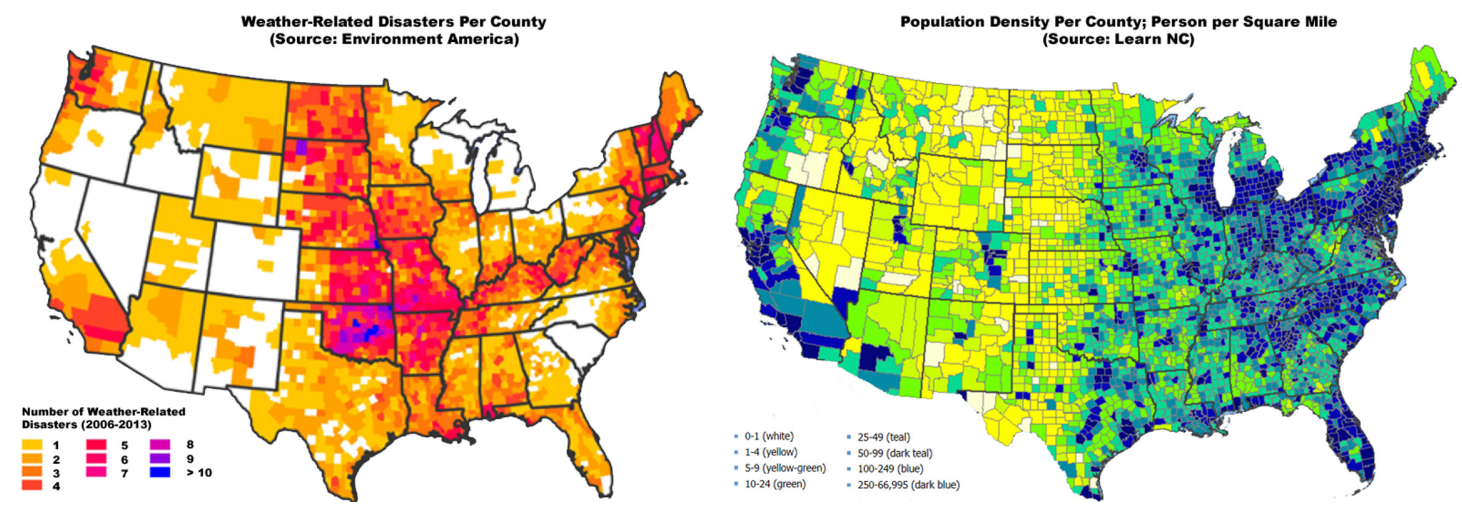

Figure 1. Weather Related Disasters and Population Density, By County The figure shows the number of weather related disasters (left panel) and population density (right panel), by U.S. county. Weather related disasters include flooding, tropical cyclones, fire, tornadoes, and other severe storms. The data on weather related disasters cover the 2006-2013 period and are retrieved from Environment America. The data on population density are measured at the end of 2000 and are retrieved from NC Learn.

out the possibility that firms relocate away from hurricane-affected areas and thus ensuring that firms are randomly assigned to treatment. Second, the origins of and paths taken by hurricanes must be virtually impossible to predict, ruling out the possibility that firms react to hurricane strikes before they occur, which would contaminate the pre-event period. Third, hurricane strikes must meaningfully affect the distress risk of firms located in the struck areas ("inclusion restriction"). Fourth, hurricane strikes must affect a firm's risk choices only through increasing distress risk, and not through other channels ("exclusion restriction").

The condition that hurricanes must have an effect on a large number of U.S. areas is likely to be fulfilled. Blake, Landsea, and Gibney (2011) show that hurricanes do not only damage coastal regions, but also spawn storms and tornadoes damaging inland regions. In addition, hurricanes often cause flooding due to them being accompanied by heavy rainfalls. In accordance, Dessaint and Matray (2017) find that only about half of all U.S. counties have never been affected by a hurricane over the last 150 years. Figure 1 shows that even fewer counties have never been affected by weather-related disasters including, but not limited to, hurricanes. More importantly, it further shows that counties not affected by weather-related disasters tend to be sparsely populated, making them unattractive locations for firms to move to. 
The condition that the origins of and paths taken by hurricanes must be virtually impossible to predict is also likely to be fulfilled. The National Center for Atmospheric Research (NCAR) argues that hurricane incidences are challenging to forecast because "small-scale features [such as minor variations in the atmosphere] either nurture or crimp a potential hurricane." Moreover, the National Hurricane Center (NHC) reports that around half of all five-day ahead forecasts of a hurricane's location are off-target by more than 200 miles.

The condition that hurricanes must significantly affect firms' distress risk is also likely to be fulfilled given the massive economic damages caused by hurricanes. For example, Pielke, Wigley, and Green (2008) and Blake, Landsea, and Gibney (2011) find that Hurricane Katrina caused an estimated property damage of $\$ 113$ billion. In accordance, Property Claims Services reports that seven out of the ten most costly U.S. catastrophes were hurricanes. Studying data on all hurricanes and tropical storms between 1994 and 2015, they report that total insured hurricane losses amounted to $\$ 161.2$ billion or $40.8 \%$ of total insured losses. Finally, Hsiang and Jian (2014) report that hurricanes cause long-lasting declines in economic growth. ${ }^{10}$

The problematic condition is that hurricanes must affect our analysis variables only through increasing distress risk, but not through any other channels. This condition would be violated if, for example, hurricanes more strongly damaged tangible assets (e.g., vehicles, machines, and structures) than intangible assets, and tangible assets were less risky than intangible assets. In this case, hurricane strikes would increase our first risk proxy, FirmRisk, simply because they caused managers to write down low-risk tangible assets. More directly capturing deliberate managerial investment decisions, our second risk proxy, InvestmentRisk, is, fortunately, immune to effects induced through the damages caused by hurricanes. Nevertheless, both risk proxies suffer from the problem that hurricanes affect firms along multiple dimensions. For example, a

\footnotetext{
${ }^{10}$ In Hsiang and Jian's (2014, p.4) own words: "We find that GDP growth rates are depressed for the fifteen years that follow a cyclone strike, causing the trajectory of long-run income to deviate significantly from its pre-disaster trend. Within the 20 years following a cyclone there is no rebound in growth, so affected national incomes remain permanently lower than their disaster-free counterfactuals."
} 
hurricane strike may affect a firm's product markets, labor markets, and growth opportunities, perhaps prompting managers to rethink the firm's business model and spurring changes in firm risk not driven by risk-shifting considerations. In the next subsection, we describe how our differences methodology attempts to mitigate the effects of such problems.

\subsection{The Differences Methodology}

We use a differences methodology similar to Bertrand and Mullainathan (2003), but adjusted for us relying on two identification contrasts instead of one, to study whether distress risk prompts industrial firms to shift towards riskier assets. Our methodology features several, sometimes overlapping, shock periods and several, sometimes overlapping, groups of treated firms. For example, since both Hurricanes Ophelia and Rita spawned in 2005, they yield identical shock periods. However, while Hurricane Ophelia struck firms in North Carolina, Hurricane Rita struck firms in Florida, Louisiana, and Texas. For each hurricane season, our first identification contrast is between hurricane-struck firms and non-hurricane-struck firms. Conversely, our second is between pre-hurricane-strike healthy firms and pre-hurricane-strike distressed firms.

Starting with the first identification contrast, our treatment-firm sample contains firm-year observations associated with firms located in a county struck by a hurricane over the four-year period surrounding the strike (excluding the strike year). ${ }^{11}$ Denoting the strike year as year 0 , the pre-hurricane event period thus features year -2 and -1 , while the post-hurricane event period features year +1 and +2 . We only study two observations before and after a strike because Bertrand, Duflo, and Mullainathan (2004) show that long event periods can generate upward biased inference levels in shock-based tests. We further ensure that there is a gap of at least five years between the hurricane strikes experienced by a treated firm. If the gap is shorter, we study the event period generated by the first hurricane, but exclude the event period

\footnotetext{
${ }^{11}$ Coval and Moskowitz (1999) and Prinsky and Wang (2006) offer empirical evidence suggesting that the vast majority of firms have their "locality of operations" close to their headquarters.
} 
generated by the second. We do so because firms struck by multiple hurricanes over short time periods create problems for our methodology through generating overlap between the earlier hurricane's post-event period and the later hurricane's pre-event period. Noteworthily, the five-year gap ensures that our treated firms are not regularly struck, decreasing the probability that the firms have taken significant precautionary measures against hurricanes.

For each hurricane season, we match the treated firm-year observations with firm-year observations associated with firms located in counties not struck by hurricanes over the same period (the control observations). To mitigate indirect effects of hurricanes, we exclude from the matched observations those associated with firms located in the five counties closest to each struck county. ${ }^{12}$ We use the Haversine formula (i.e., the great circle distance between two points on a sphere given their longitudes and latitudes) to calculate the distance between counties. Our matching choices imply that a firm can act as both treated and control, albeit in different hurricane seasons, and that it can act as either multiple times. We define Treated $d_{i, t}$ to be a dummy variable equal to one for observations associated with the hurricane-struck firms and equal to zero for observations associated with the matched controls.

Our second identification contrast compares pre-hurricane-strike healthy firms and prehurricane-strike distressed firms. Assuming that healthy firms are identical to distressed firms except along the distress risk dimension, the second contrast differences out the effects of hurricane strikes arising through non-distress-risk channels, mitigating the concern that our tests violate the exclusion restriction. To classify firms according to their distress risk, we sort them into portfolios based on their DistressRisk values at the end of the fiscal year before a hurricane strike year. Doing so, we ensure that we only use pre-hurricane data to determine

\footnotetext{
${ }^{12}$ The indirect effects of hurricanes can be positive or negative. Competitors located in counties neighboring a hurricane-struck county may, for example, benefit from a strike, while customers or suppliers located in such counties may suffer. In addition, hurricane-induced damages to the infrastructure of a county, as, for example, its roads and bridges, may also negatively affect firms in neighboring counties if those firms rely on the infrastructure (e.g., if they have to transport their output through the hurricane-struck county).
} 
treatment status. To allow for a non-linear effect of distress risk on our analysis variables, we sort firms into three portfolios. The first portfolio contains firms with a DistressRisk value below the sixth decile ("healthy firms"); the second portfolio contains firms with a value between the sixth and the ninth deciles ("ailing firms"); and the third portfolio contains firms with a value above the ninth decile ("distressed firms"). ${ }^{13}$ We use the healthy firms as control firms. We define Healthy (Ailing) [Distressed] to be a dummy variable equal to one if a firm belongs to the healthy (ailing) [distressed] firm portfolio, and else zero.

A possible caveat with our second identification contrast is that healthy and distressed firms may not only differ along the distress risk dimension, but also along other dimensions. To alleviate this concern, we repeat our tests on a within-industry propensity-score (PS) matched sample of healthy and distressed firms. To form the PS-matched sample, we use a logit model of a dummy variable equal to one if a firm's DistressRisk value is above the sixth decile and else zero, on Size, Age, and PPEE. We estimate the logit model separately by one-digit SIC code industry using data from the year before a hurricane strike (year -1$)$. We match each above-sixth-decile DistressRisk value firm with the below-sixth-decile DistressRisk value firm from the same one-digit SIC code industry and with the closest fitted probability. ${ }^{14}$

We start our empirical analysis with a simple comparison of mean values. To do so, we first calculate the mean values of our analysis variables for the hurricane-struck firms $($ Treated $=1)$ by distress risk portfolio and pre- or post-hurricane period. We next calculate the difference in the mean values from the pre- to the post-hurricane period by distress risk portfolio. We finally

\footnotetext{
${ }^{13}$ We acknowledge that our choices for the portfolio breakpoints are adhoc. In the Internet Appendix, we therefore show that varying the portfolio breakpoints does not change our conclusions. Interestingly, however, raising the lower breakpoint of the ailing firms and thus boosting their distress risk significantly strengthens our evidence that these firms take on more risk in response to exogenous distress risk increases.

${ }^{14}$ Adding other covariates to the logit model, such as FirmRisk, InvestmentRisk, and BookToMarket, does not materially change the PS-matched sample. Neither does separately estimating the logit model by the combination of hurricane-struck or non-hurricane-struck county and one-digit SIC code industry.
} 
calculate the difference in the difference from the pre- to post-hurricane period ("DID") between the ailing and the healthy firms or the distressed and the healthy firms. Repeating the same steps for the non-hurricane-struck firms $($ Treated $=0)$, we calculate "counterfactual" DID estimates. Subtracting each non-hurricane-struck firm DID estimate from its corresponding hurricane-struck firm DID estimate, we obtain DIDID estimates. Both the DID and the DIDID estimates allow us to assess the causal effect of distress risk on our analysis variables.

To control for other variables and firm- and year-fixed effects, we also use regressions to calculate the DIDID estimates. Allowing the effects of the controls and the fixed effects to vary across the healthy, ailing, and distressed firms, we write the regression model as:

$$
\begin{aligned}
\text { AnalysisVariable }_{i, t} & =\alpha_{i, k}+\alpha_{t, k}+\boldsymbol{\beta}^{\prime} \text { Distress }_{i, t} \times \text { Treated }_{i, t} \times \text { After }_{i, t} \\
& +\boldsymbol{\gamma}^{\prime} \text { Distress }_{i, t} \times \text { Treated }_{i, t}+\boldsymbol{\delta}^{\prime} \text { Distress }_{i, t} \times \text { After }_{i, t} \\
& +\boldsymbol{\eta}^{\prime} \text { Distress }_{i, t} \otimes \mathbf{X}_{i, t}+\varepsilon_{i, t},
\end{aligned}
$$

where Analysis Variable is firm $i$ 's analysis variable in year $t$, Distress $=[1, \text { Ailing, Distressed }]^{\prime}$, After is a dummy variable equal to one for the two years after a hurricane strike (i.e., year +1 and +2 ), and else zero, and $\mathbf{X}_{i, t}$ is a vector of controls. $\otimes$ is the Kronecker product. $\boldsymbol{\beta}, \boldsymbol{\gamma}$, $\boldsymbol{\delta}$, and $\boldsymbol{\eta}$ are vectors of parameters, $\alpha_{i, k}$ are firm-distress risk portfolio fixed effects, $\alpha_{t, k}$ are year-distress risk portfolio fixed effects, and $\varepsilon_{i, t}$ is the residual. We use White's (1980) formula to calculate standard errors. ${ }^{15}$ We can interpret the $\beta$ coefficient on the triple interaction involving Ailing as the causal effect of distress risk on the analysis variable for ailing firms. In the same vein, we can interpret the $\beta$ coefficient on the triple interaction involving Distressed as the causal effect of distress risk on the analysis variable for distressed firms.

\footnotetext{
${ }^{15}$ Our results are robust to excluding the controls. They are also robust to replacing the firm fixed effects with county- or state-fixed effects or clustering standard errors at the firm-, industry-, or county-level.
} 


\section{Data Sources}

We obtain market data from CRSP and accounting data (including the geographical location of a firm's headquarters) from Compustat. Segment data are from the Compustat Historical Segment database. T-Bill rates are from Kenneth French's website. The bankruptcy filing data are from the union of SDC Platinum and bankruptcydata.com, while the performance-related delistings data are from CRSP (delisting codes 500 or 520-584). We retrieve data on the identity of counties struck by hurricanes, the strike dates, and the amount of total (property and crop) damages caused by a hurricane from the Spatial Hazard and Event Losses Database for the United States ("SHELDUS") provided by the University of South Carolina.

We create our analysis sample as follows. We start with the observations in the Compustat Historical Segment database over the 1991-2011 period. ${ }^{16}$ We next apply the following screening criteria to this sample. First, we drop firm-year observations for which the difference between the sum of a firm's segment sales and its total sales exceeds $20 \%$. Second, we drop non-operating firm-year segments and reallocate their values to the values of the remaining segments on a pro-rata basis. ${ }^{17}$ Third, we drop all firms only ever reporting information for the same single segment. Finally, considering the sample of firms switching from one single segment to another or from a single segment to multiple segments, we drop firm-year observations before the first switch if the firm starts out as a single segment firm in our data. We impose the third and fourth restrictions because single-segment firms produce a zero change in our risk proxies by

\footnotetext{
${ }^{16}$ While our sample period thus spans two segment accounting regulations, namely, SFAS 14 and SFAS 131, Rajan, Servaes, and Zingales (2000) offer evidence that the change from SFAS 14 to SFAS 131 did not lead to significant changes in the segment structures reported by most firms.

${ }^{17}$ Non-operating segments appear either for reporting adjustment purposes or serve management (rather than operational) purposes. We distinguish operating from non-operating segments using a textual algorithm searching the names of the segments for the words "corporate," "headquarters," and "adjustments." The Compustat Segment database usually assigns a firm's primary SIC code to non-operating segments, inflating the importance of a firm's core assets in the absence of our remedy.
} 
construction. We next match the segment data with Compustat data. We drop financial firms (SIC codes: 6000-6999) and utility firms (4900-4999). We also drop firm-year observations with missing DistressRisk or control variable values. In our differences analysis, we further drop firms which do not have complete data over a hurricane's event period. To alleviate the effect of outliers, we winsorize all continuous variables at the first and 99th percentiles.

We define as hurricane-struck counties those suffering hurricane damages in excess of $\$ 250,000$ (in 2013 U.S. dollars). While the $\$ 250,000$ threshold may appear low, the mean (median) damage observed by the qualifying counties is $\$ 118$ million ( $\$ 17$ million). Also, we later show that the qualifying hurricanes significantly raise firms' distress risk. Finally, increasing the damage threshold to, for example, $\$ 1$ or $\$ 2$ million, does not change our conclusions.

Our final sample includes 178 unique hurricane-struck firms and 7,331 not-necessarilyunique matched control firms. The number of hurricane-struck firms is relatively low because a large number of them do not fulfill the condition that they are not struck by other hurricanes over the two years before the hurricane strike in event year 0 .

\section{Empirical Results}

In this section, we present our empirical results. We first offer several real-world examples illustrating the behavior of our risk proxies, FirmRisk and InvestmentRisk. We next report descriptive statistics for the risk proxies and other variables. Turning to our main objective, we finally study whether distress risk prompts industrial firms to take on more risk and, if it does, how the firms raise their risk and whether this behavior affects their creditors.

\section{$5.1 \quad$ Illustrative Examples}

We first discuss several real-world examples building up intuition about the behavior of our risk proxies. The purpose of the examples is not to showcase firms raising their risk due to an 
increase in distress risk, but to illustrate that our risk proxies can yield different conclusions about whether a firm changes its risk compared to other proxies in the literature. For example, in line with a logic often espoused by corporate finance textbooks, Coles, Daniel, and Naveen's (2006), Low's (2009), and Kini and Williams's (2012) risk-taking proxies implicitly assume that a decrease in the number of operating segments always increases firm risk. In contrast, Acharya, Amihud, and Litov's (2011) risk-taking proxy, which we introduced in Section 2.1, implicitly assumes that only adding segments to a firm's segment portfolio changes firm risk.

Table 1 shows the calculations of our risk proxies for Halliburton at the end of fiscal years 2006 and 2007. Until the end of fiscal year 2006, Halliburton was a healthy diversified provider of services and products to energy, industrial, and government customers, with six operating segments. During fiscal year 2007, it, however, underwent a major restructuring, divesting non-core assets and reorganizing itself into an oil and gas field services- and a drilling oil and gas wells-segment. According to the firm's 2007 10-K report, it did so to "improve operational and cost management efficiencies, better serve our customers, and become better aligned with the process of exploring for and producing from oil and natural gas wells." Consistent with the textbook logic described above, the reduction in the number of segments raised Halliburton's FirmRisk from $27.1 \%$ to $36.3 \%$ and its InvestmentRisk from $34.1 \%$ to $36.3 \%$. The company continued to operate in these segments until the end of our sample period.

\section{TABLE 1 ABOUT HERE}

While the Halliburton example shows that decreases in the number of segments can increase firm risk, we next show that our risk proxies are not necessarily negatively related to operating diversity. For example, expanding the number of its segments from three in 1998 to five in 1999 to respond to more intense competition and new technologies, Cincinnati Bell raised its FirmRisk from $27.6 \%$ to $35.7 \%$ and its InvestmentRisk from $27.5 \%$ to $30.2 \%$, opposite of what the textbook logic suggests. The higher risk was spurred by the company expanding into 
segments riskier than its original segments. The risk proxies can change even in the absence of a change in the number of segments. For example, while owning five segments in both 1992 and 1993, Scott Technologies decreased both its firm and investment risk by about three percentage points over that period. It did so by swapping two higher-risk segments for two lower-risk segments to respond to a deterioration in its profitability. As a final example, while owning the same operating segments in both 2004 and 2005, Ralph Lauren increased both its firm and investment risk over that period by skewing its asset mix towards its higher-risk segments to respond to strong growth in its retail business. The final example illustrates that, different from Acharya, Amihud, and Litov's (2011) risk-taking proxy, the identity of a firm's segments does not need to change for our firm or investment risk proxies to change. ${ }^{18}$

\subsection{Descriptive Statistics}

Table 2 offers descriptive statistics on our risk proxies and other variables. The table suggests that the average firm's operating segment portfolio has a volatility of about $29.7 \%$ (FirmRisk), while its new real-assets portfolio has a volatility of about 30.0\% (InvestmentRisk), both per annum. Because most firms only own a small number of segments, both volatility estimates are only slightly below the corresponding value-weighted averages of the volatilities of the segments, implying that most firms do not greatly benefit from diversification benefits (not shown). While the median firm has an essentially zero one-year ahead default probability, the mean firm has a default probability of about $6.7 \%$ (DistressRisk).

\section{TABLE 2 ABOUT HERE}

The table also reports descriptive statistics for FirmRisk, InvestmentRisk, and DistressRisk separately for the healthy, ailing, and distressed firms. These statistics demonstrate that both

\footnotetext{
${ }^{18}$ To save space, we do not offer background information on why the companies mentioned in this paragraph changed their risk nor on what happened to them. See the Internet Appendix for this information.
} 


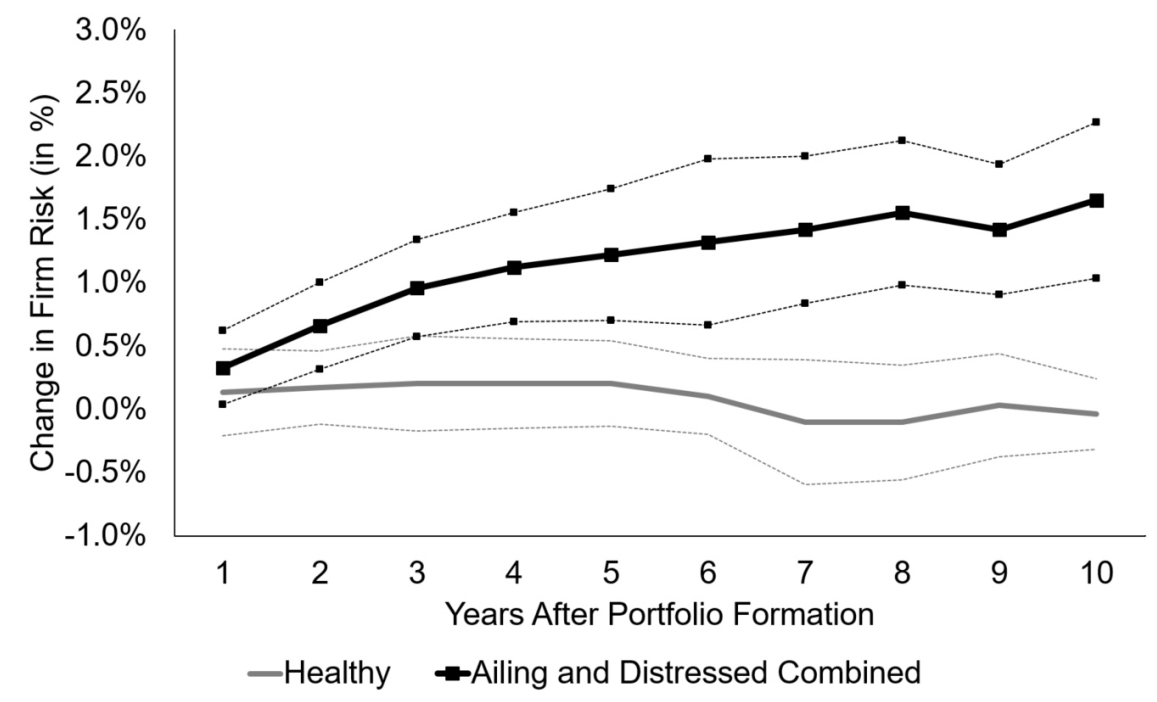

Figure 2. Changes in Firm Risk, By Distress Risk Groups The figure shows the change in mean FirmRisk from year zero to up to ten years into the future for healthy and ailing/distressed firms. We define as healthy (ailing/distressed) those firms with a DistressRisk value below (above) the sixth decile at the end of year zero. The broken lines are $95 \%$ confidence bands. We first average the change in FirmRisk by group, look-ahead period, and fiscal year and then by group and look-ahead period alone.

FirmRisk and InvestmentRisk tend to rise with distress risk, consistent with a higher distress risk amplifying the incentive to take on more risk. While the healthy firms have DistressRisk values essentially equal to zero, the ailing firms have an average DistressRisk value of about $5.9 \%$ and the distressed firms have an average value of about $53.4 \%$.

Table 2 finally shows that the median firm has a total assets value (Assets) of about $\$ 251$ million and a market capitalization (Equity) of about $\$ 203$ million. Conversely, its book-tomarket ratio (BookToMarket) is about $53 \%$, while its property, plant, and equipment-to-total assets ratio $(P P \mathscr{E} E)$ is about $22 \%$. In comparison to the CRSP-Compustat universe, our sample composition is therefore skewed towards larger firms, primarily owing to the fact that larger firms are more likely to own more than one segment than smaller firms.

Figure 2 shows the cumulative percentage-point changes in FirmRisk over several future periods separately for high and low distress risk firms. At the end of each fiscal year in our sample period, we classify firms as high or low distress risk based on DistressRisk, using the 
sixth decile of the DistressRisk distribution as breakpoint. ${ }^{19}$ We then calculate each firm's cumulative change in FirmRisk over periods extending up to ten years into the future by compounding annual changes. We finally average the firm-specific changes first by fiscal year end, look-ahead period, and high or low distress risk and then by look-ahead period and high or low distress risk. The figure suggests a positive relation between ex-ante DistressRisk and ex-post FirmRisk. In particular, while the low distress risk firms do not significantly raise their FirmRisk over the five or ten years after portfolio formation, the high distress risk firms significantly raise theirs by 1.2 and 1.6 percentage points over those periods, respectively.

Reversing the exercise, we next classify firms based on whether their changes in FirmRisk over the prior five years are above or below the median change at the end of a fiscal year. Using the same methodology as above, we then study the evolutions of the average DistressRisk of these two types of firms over periods extending up to ten years into the future. Untabulated tests suggest a positive relation between ex-ante FirmRisk and ex-post DistressRisk. In particular, the firms with an above-median past increase in FirmRisk observe a two (six) percentage points greater increase in their average DistressRisk over the first five (ten) years after portfolio formation than the firms with a below-median past increase.

Our two sorting exercises illustrate why it is so difficult to establish the causal relation between distress risk and risk-taking. While the distress risk sort suggests that a high distress risk leads firms to raise their risk, the sort based on past changes in firm risk suggests that risk-taking leads to increases in future distress risk. Standard tests are thus unable to determine whether it is a high distress risk that causes risk-taking or whether it is risk-taking that causes high distress risk. In addition, standard tests are also unable to rule out that both distress risk and risk-taking are driven by an omitted third variable ("endogeneity problem").

\footnotetext{
${ }^{19}$ The low distress risk firms are thus identical to our healthy firms. We do not distinguish between ailing and distressed firms in the figure to avoid overcrowding it. Separately considering the latter firms, the distressed firms produce insignificantly more positive future changes in FirmRisk than the ailing firms.
} 


\subsection{Does Distress Risk Cause Risk-Shifting?}

\section{3.a. The Effect of Hurricane Strikes on Distress Risk}

In this section, we study whether distress risk causes industrial firms to take on more risk and, if it does, whether the risk-taking translates into risk-shifting. We start by offering evidence that hurricanes significantly raise distress risk, as required by the inclusion restriction. To do so, Figure 3 plots the average of DistressRisk for the hurricane-struck firms and the matched controls over a period starting from one year before a strike to three years after, with event month zero being the strike month. To avoid survivorship bias, we use all firm-year observations with non-missing DistressRisk in the figure. Also, since firms do not know ex-ante whether they will be struck again after event month zero, we allow for other hurricanes in the post-event period, but, to be consistent with our main tests, not in the pre-event period. ${ }^{20}$

Figure 3 suggests that hurricane strikes significantly raise the distress risk of the hurricanestruck firms relative to the distress risk of the controls. While the hurricane-struck firms and the controls have a similar and only insignificantly different mean distress risk of about six to seven percent before a strike, the mean distress risk of the hurricane-struck firms sharply rises starting from the strike month, with it increasing from $7.5 \%$ one month before a strike to $11.4 \%$ two, and a maximum of $14.3 \%$ nine, months after. Conversely, the mean distress risk of the controls rises only mildly, from $6.3 \%$ one month before a strike to a maximum of $8.3 \%$ nine months after. Crucially, the difference in mean distress risk between the two types of firms is usually significant over the first nine months after a strike, as suggested by the confidence bands in the figure. Starting from nine months after a strike, the mean distress risk of the hurricane-struck firms begins declining again. Importantly, however, it remains well above the mean distress risk range of these firms before a strike. Also, it remains well above the mean distress risk of the controls after a strike, with the difference between the two types of firms still being significant 36 months after a strike. Overall, hurricanes thus do not only have a

\footnotetext{
${ }^{20}$ Excluding firms that are struck again after event month zero has virtually no effect on the figure.
} 


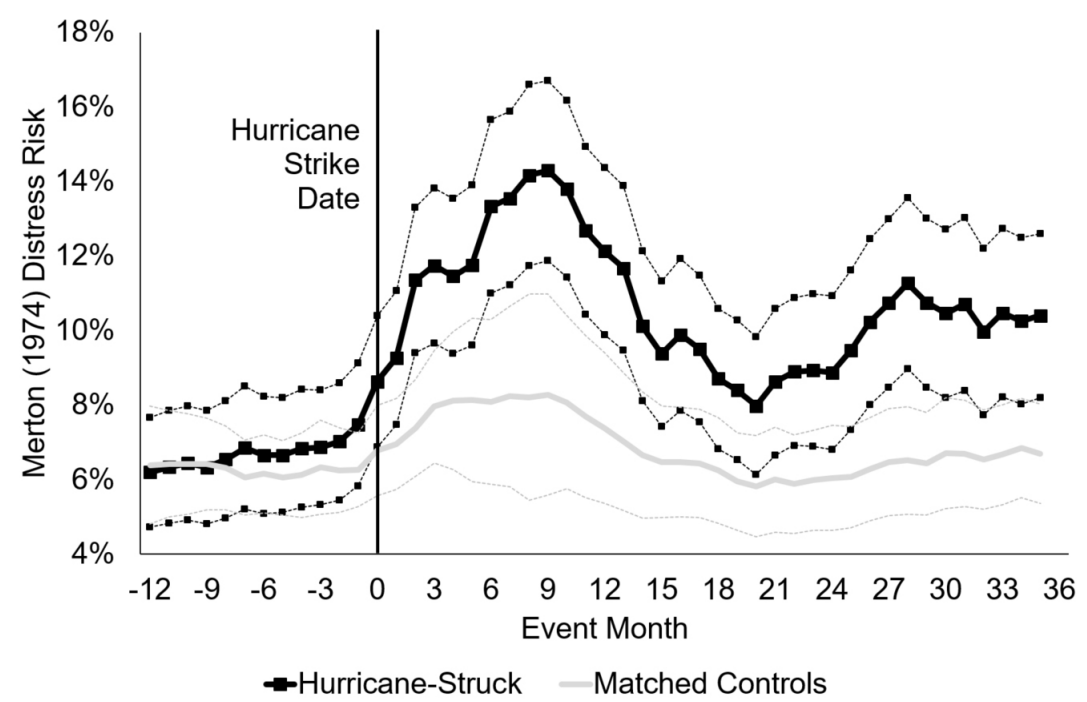

Figure 3. The Effect of Hurricane Strikes on Distress Risk The figure plots the mean DistressRisk of hurricane-struck firms and matched non-hurricane-struck firms over a four-year period surrounding a hurricane strike. The broken lines are $95 \%$ confidence bands. We first average DistressRisk by hurricane season, event month, and distress risk group and then by event month and distress risk group alone.

significant, but also a persistent, effect on the distress risk of hurricane-struck firms.

\section{3.b. The Causal Effect of Distress Risk on Risk-Taking}

In this section, we use differences tests to study whether distress risk causes firms to take on more risk. To achieve this goal, Table 3 offers the results of differences tests calculated from sample means, with Panel A looking at FirmRisk and Panel B at InvestmentRisk. The rows of the table show means calculated separately for the hurricane-struck firms (Treated $=1$ ) and the matched controls $($ Treated $=0)$ and the two years before a strike year $($ After $=0)$ and the two years after $($ After $=1)$. Conversely, the columns show means calculated separately for the healthy $($ Healthy $=1)$, ailing $($ Ailing $=1)$, and distressed $($ Distressed $=1)$ firms.

\section{TABLE 3 ABOUT HERE}

Panel A of Table 3 suggests that, over the two years before a hurricane strike, the healthy, ailing, and distressed hurricane-struck firms have an average operating segment portfolio risk 
(FirmRisk) of $30.2 \%, 28.5 \%$, and $30.4 \%$, respectively. Comparing these numbers with averages calculated over the two years after a strike, both the healthy and distressed hurricane-struck firms observe only insignificant changes in their average operating segment portfolio risk, with the average risk of the healthy firms rising by 0.2 percentage points and the average risk of the distressed firms falling by 0.3 points. In stark contrast, the average risk of the ailing hurricane-struck firms rises significantly by 1.2 points ( $p$-value: 0.014$)$. In comparison, the mean risk of the non-hurricane-struck firms rises by between 0.2 to 0.4 points from the two years before a strike to the two years after, suggesting that the healthy hurricane-struck firms behave similarly to firms not exposed to an exogenous increase in distress risk.

A concern with the changes in FirmRisk in Panel A is that they may not be caused by deliberate managerial actions, but by the hurricanes themselves. If tangible assets were, for example, both less risky and more susceptible to hurricane damages than intangible assets, then hurricanes could directly cause the changes in FirmRisk if ailing firms were also more tangible-asset intensive than other firms. Hurricanes could also directly cause the changes in FirmRisk if the ailing firms' core segments were both more affected by hurricanes due to a greater proximity to the firms' headquarters, but also less risky than their newer segments, perhaps due to pre-hurricane-strike risk-shifting. Fortunately, using our alternative risk proxy InvestmentRisk, which is calculated from managers' actual investments into segments and is thus immune to the direct effects caused by hurricanes, we are able to immediately rule out this concern. In particular, Panel B of Table 3 suggests that the changes in InvestmentRisk observed by the differently distressed hurricane-struck or non-hurricane-struck firms are similar to their corresponding changes in FirmRisk in Panel A. For example, the average new real-assets portfolio risk of the ailing hurricane-struck firms rises by about 1.2 percentage points from before a hurricane strike to after ( $p$-value: 0.002$)$, which is virtually identical to these firms' increase in average operating segment portfolio risk over the same period.

To calculate DIDID estimates, we first take the difference between the change in FirmRisk 
of the ailing hurricane-struck firms from before a hurricane strike to after and the change of the healthy hurricane-struck firms over the same period. The result is a significant 0.92 ( $p$-value: 0.072; see Panel A). Repeating the calculations using non-hurricane-struck firms, we obtain an insignificant estimate of 0.04. Subtracting 0.04 from 0.92 , we obtain a significant DIDID estimate for the ailing firms' FirmRisk of 0.88 ( $p$-value: 0.078$)$. Swapping the ailing firms for the distressed firms and redoing the above calculations, we obtain an insignificant DIDID estimate for the distressed firms' FirmRisk of -0.74. Turning to the other risk proxy, InvestmentRisk, we obtain a significant DIDID estimate for the ailing firms of 1.15 ( $p$-value: 0.014), but an insignificant DIDID estimate for the distressed firms of -0.50 (see Panel B).

In Table 4, we repeat the DIDID calculations using regressions featuring control variables and firm- and year-fixed-effects (see Equation (6)). The model estimated in columns (1) to (3) uses FirmRisk as dependent variable, while the model estimated in columns (4) to (6) uses InvestmentRisk. Supporting the sample-mean based evidence, the table suggests that the ailing firms significantly raise both their FirmRisk and InvestmentRisk in response to a hurricane strike. In particular, the coefficient on the triple interaction involving Ailing, which is the DIDID estimate for the ailing firms, is a highly significant 0.86 in the model explaining FirmRisk ( $p$-value: 0.018) and a highly significant 1.24 in the model explaining InvestmentRisk ( $p$-value: 0.002). In contrast, the distressed firms decrease their risk in the same situation, with, however, only the decrease in FirmRisk being significant. In particular, the coefficient on the triple interaction involving Distressed, which is the DIDID estimate for the distressed firms, is a significant -1.13 in the model explaining FirmRisk ( $p$-value: 0.040), but an insignificant -0.58 in the model explaining InvestmentRisk. Of the control variables, we find some evidence suggesting that both risk proxies decrease with Size and PPEE.

\section{TABLE 4 ABOUT HERE}

A remaining concern with our results in Tables 3 and 4 is that the healthy, ailing, and 
distressed firms may not only differ along the distress risk dimension, but also along other dimensions, possibly biasing our estimates. To mitigate this concern, we next repeat the DIDID regressions on a PS-matched sample, ensuring that the differently distressed firms are similar in terms of their size, age, asset tangibility, and industry composition. Table 5 shows that, while the PS-matched sample contains only about 14,000 observations compared to about 26,000 in our original sample, it yields inferences in complete agreement with those produced by our original sample. In particular, the DIDID regressions on the PS-matched sample also suggest that the ailing firms significantly raise both their FirmRisk and InvestmentRisk in response to a hurricane strike, while the distressed firms decrease theirs. Different from before, the decreases in the risk proxies observed by the distressed firms are, however, both insignificant now.

\section{TABLE 5 ABOUT HERE}

In sum, our differences analysis suggests an inverted U-shaped relation between distress risk and risk-taking, with only the ailing, but not the distressed, firms reacting to a hurricane strike by taking on more risk. In fact, if anything, the distressed firms seem to react by lowering

their risk. Importantly, the risk-taking of the ailing firms is not only statistically, but also economically, significant, with their changes in both FirmRisk and InvestmentRisk lying above the 90th percentiles of the full-sample distributions of changes in the variables. We will shed more light on the behavior of the distressed firms later on in the paper.

\section{3.c. How Do the Ailing Firms Take On More Risk?}

We next study how the ailing hurricane-struck firms take on more risk. Viewing a firm as a portfolio of operating segments, a firm can raise its risk by shifting towards riskier assets, either by opening up or expanding high-risk segments or by closing down or contracting low-risk segments. Alternatively, the firm can shift towards more correlated assets, for example, by lowering the number of segments owned by it. To identify which of these strategies are used 
by the ailing hurricane-struck firms, we reestimate DIDID regression (6) using Capex, Focus, NumberSegments, Cash, and AcquisitionExpense as new dependent variables.

$\overline{\text { TABLE } 6 \text { ABOUT HERE }}$

Column (1) of Table 6 suggests that the ailing hurricane-struck firms tend to raise their capital expenditures from before to after a hurricane strike, with these firms' DIDID estimate on Capex being a significant 0.023 ( $p$-value: 0.037$)$. Some of the extra capital expenditures appear to be used to change the firms' business orientation. Column (2), for example, suggests that the ailing hurricane-struck firms tend to become about twelve percentage points more likely to change their two-digit SIC focus ( $p$-value: 0.033) after a strike, while column (3) suggests that they close an average of one-fifth of a segment ( $p$-value: 0.017). Importantly, however, column (4) offers no evidence suggesting that the firms close down segments to start hoarding cash, refuting the concern that our risk-taking evidence is spuriously driven by our risk proxies not taking cash balances into account. Similarly, column (5) offers no evidence suggesting that the risk-taking of the ailing hurricane-struck firms is facilitated through M\&A activity. ${ }^{21}$

Table 6 further shows that the distressed hurricane-struck firms also tend to restructure themselves after a hurricane strike. In particular, while we find no evidence that these firms change their number of segments, they become almost 30 percentage points more likely to change their two-digit SIC focus ( $p$-value: 0.002). Moreover, our evidence also suggests that they start running down their cash balances after a strike ( $p$-value: 0.001$)$.

\footnotetext{
${ }^{21}$ To offer further evidence on M\&As, we have also used SDC Platinum deals data excluding exchange offers and share buybacks to study whether hurricane strikes affect a firm's propensity to act as acquirer or target in an M\&A deal. Separately considering mergers and acquisitions and firm-initiated and non-firminitated deals, we have calculated the number of deals in which a firm is involved over the two years before a hurricane strike and the two years after and then averaged over the differently-distressed hurricane-struck or non-hurricane-struck firms. Our results suggest that, while hurricane-struck firms tend to become significantly less likely to acquire other firms after a strike, the other probabilities do not significantly change.
} 
Overall, our conclusion is that the changes in FirmRisk and InvestmentRisk of the ailing and distressed firms found in Section 5.3.b. are attributable to these firms refocussing themselves, with the ailing, but not the distressed, firms closing down segments in that process. While the ailing firms, however, tend to refocus themselves towards segments raising their risk, the distressed firms tend to refocus themselves towards segments lowering their risk.

\section{3.d. Does the Ailing Firms' Risk-Taking Hurt Their Creditors?}

Our evidence so far suggests that ailing firms take on more risk in response to distress risk increases induced through hurricane strikes. We now offer evidence from three further tests suggesting that this behavior hurts the ailing firms' creditors through lowering the value of their positions, indicating that the ailing firms not only raise risk, but, in fact, risk-shift.

In our first test, we show that the ailing firms make value-reducing investment decisions to raise their risk, lowering their investment efficiency and the chance that they can repay their creditors in the future. To do so, Table 7 offers the results from reestimating DIDID regression (6) using Average $Q^{\text {Firm }}$ or Average $Q^{\text {NewAssets }}$ as new dependent variables. Columns (2) and (5) show that the ailing firms skew their asset mixes and their new real-assets portfolios towards segments with lower average Qs - and thus worse growth opportunities - after a hurricane strike. In particular, the coefficient on the triple interaction involving Ailing is -0.38 in the model explaining Average $Q^{\text {Firm }}$ ( $p$-value: 0.000 ), while it is -0.33 in the model explaining Average $Q^{\text {NewAssets }}$ ( $p$-value: 0.002). Conversely, columns (3) and (6) show that the distressed firms skew their asset mixes and new real-assets portfolios towards segments with higher average Qs - and thus better growth opportunities — in the same situation. In particular, the coefficient on the triple interaction involving Distressed is 0.23 in the model explaining Average $Q^{\text {Firm }}$ ( $p$-value: 0.203 ), while it is 0.34 in the model explaining Average $Q^{\text {NewAssets }}(p$ value: 0.074 ). Different from the ailing firms, the distressed firms thus improve their investment 
efficiency after a strike, increasing their ability to repay their creditors in the future.

\section{TABLE 7 ABOUT HERE}

In our second test, we show that hurricanes prompt ailing firms to invest into segments not only characterized by few growth opportunities, but also a tendency to raise failure risk. To achieve this goal, Figure 4 plots cumulative failure rates for the matched non-hurricane-struck firms (Panel A) and the hurricane-struck firms (Panel B) from the start of the third fiscal year after a hurricane strike to eight years into the future, in both cases separately reporting failure rates for healthy, ailing, and distressed firms. ${ }^{22}$ Starting with the non-hurricane-struck firms, Panel A of Figure 4 suggests that a higher Merton (1974) DistressRisk value in event year -1 leads to a higher failure probability in event years +3 to +10 , consistent with these firms not changing their risk in event years 0 to $+2 .{ }^{23}$ In contrast, Panel B suggests that, despite having an only moderate DistressRisk value in event year -1, the ailing hurricane-struck firms are marginally more likely to fail than the distressed hurricane-struck firms over event years +3 to +10 , consistent with them significantly raising their risk in event years 0 to +2 .

More specifically, while about $23 \%$ of the ailing non-hurricane-struck firms fail until the end of event year +10 , about $33 \%$ of the distressed non-hurricane-struck firms do so, too, with the difference in failure rates across these two groups of firms being highly significant ( $p$-value: 0.000). Further, while about $35 \%$ of the ailing hurricane-struck firms fail until the end of event year +10 , only about $29 \%$ of the distressed hurricane-struck firms do so, too, with the difference

\footnotetext{
${ }^{22}$ We start the calculation of the failure rates from event year +3 since our restriction that a firm must have complete data over a hurricane's event period from event year -2 to +2 to be included in our differences tests implies that there are no failures over event years +1 and +2 .

${ }^{23}$ This result is consistent with the findings of, for example, Vassalou and Xing (2004) and Aretz, Florackis, and Kostakis (2017), which show that, in general, a higher Merton (1974) default probability at the end of month $t$ leads to a higher probability of a firm failing starting from the beginning of month $t+1$.
} 
Panel A: Non-Hurricane-Struck Counties

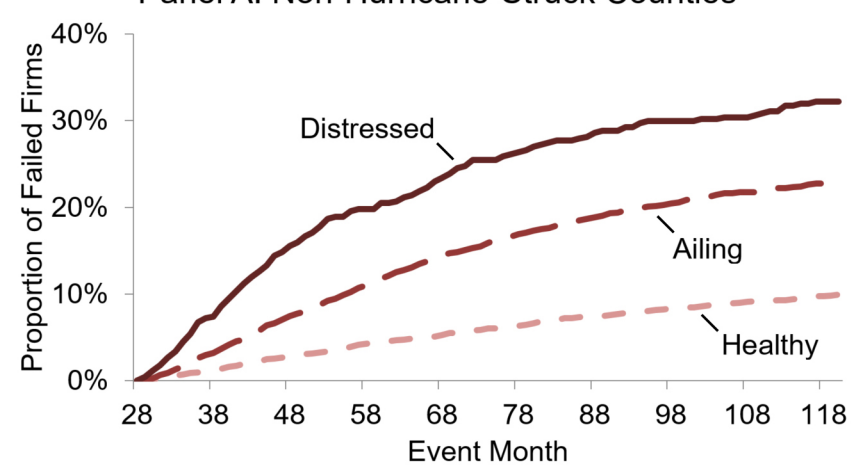

Panel B: Hurricane-Struck Counties

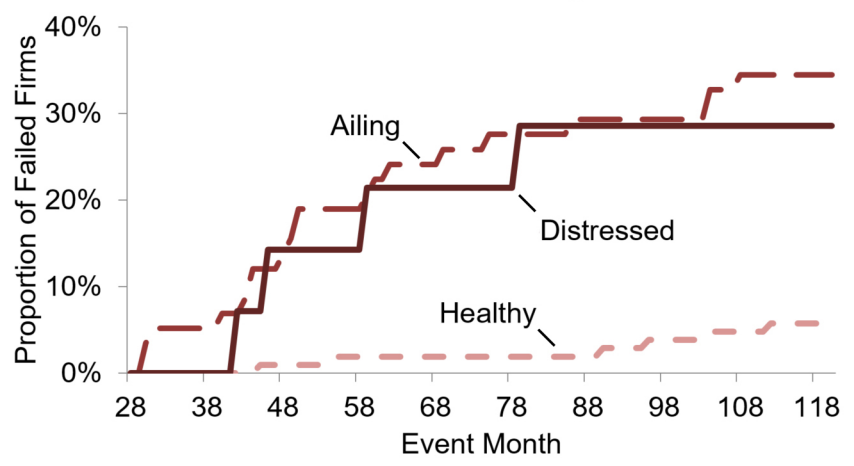

Figure 4. Failure Rates The figure plots cumulative failure rates for the matched non-hurricane-struck firms (Panel A) and the hurricane-struck firms (Panel B) over event years +3 to +10 , separately reporting the failure rates for healthy, ailing, and distressed firms. The healthy (ailing) [distressed] firms are firms with a DistressRisk value below the sixth decile (between the sixth and ninth deciles) [above the ninth decile] at the end of event year -1 (i.e., the year before the hurricane-strike year). We define failures as bankruptcy filings, performance-related stock market delistings, and distressed mergers (defined in Section 4.).

in failure rates across these two groups of firms being insignificant. Finally, the difference in failure rates between the ailing hurricane-struck firms and the ailing non-hurricane-struck firms is again highly significant ( $p$-value: 0.038). Overall, our conclusion is that the risk-taking of the ailing firms in response to a hurricane strike leads to a statistically and economically meaningful increase in their average failure risk of above ten percentage points, significantly decreasing the chance that these firms can repay their creditors in the future.

In our final test, we study why the distressed firms respond so differently to a hurricane strike relative to the ailing firms, to provide one last piece of evidence that the ailing firms' risk-taking hurts their creditors. Chava and Roberts (2008) show that creditors actively intervene in the investment decisions of firms that have violated financial covenants in the past. Relatedly, Gilje (2016) shows that creditor control induced through covenant violations may explain why oil and gas firms lower their risk in response to exogenous increases in their leverage. We thus speculate that creditor control induced through covenant violations also prevents distressed, but not ailing, firms from raising their risk after a hurricane strike. Using covenant violation data from 1996 to 2011 from Michael Roberts' website,${ }^{24}$ we find some initial evidence consistent with

\footnotetext{
${ }^{24}$ The URL address is: <http://finance.wharton.upenn.edu/ mrrobert/>.
} 
this hypothesis. While only about $18 \%$ of the ailing firms have violated covenants over event years -2 and -1 , about $52 \%$ of the distressed firms have done so, too, suggesting that distressed firms are far more likely to be under creditor control than ailing firms.

More importantly, we next rerun DIDID regression (6) on FirmRisk and InvestmentRisk separately using either the subsample of ailing firms that have complied with their covenants over event years -2 and -1 or the subsample of ailing firms that have violated some of their covenants over that period as treatment group. Noting that the covenant data begin after the start of our original sample period (1996 vs. 1992), we use a two-year look-back period to identify covenant violations to keep our sample period as long as possible. Also, since the distressed firm portfolio contains too few firms to be split, we drop these firms and all variables involving Distressed from the regression. ${ }^{25}$ Table 8 shows the results from these regressions, with columns (1) and (4) offering the full-sample results, columns (2) and (5) those using the ailing compliers, and columns (3) and (6) those using the ailing violators.

\section{TABLE 8 ABOUT HERE}

While the full sample in Table 8 contains only about 19,000 observations compared to about 26,000 in our original tests, columns (1) and (4) corroborate the result that ailing firms raise their risk after a hurricane strike, while distressed firms either do not change their risk or decrease it. More importantly, the table also offers strong evidence suggesting that covenant violations condition the effect of distress risk on risk-taking. While the ailing compliers in

${ }^{25}$ Also splitting the distressed firms into two groups based on whether they have violated financial covenants over event years -2 and -1 and separately running DIDID regression (6) using either the ailing and distressed compliers or the ailing and distressed violators as treatment groups, we are, unfortunately, not able to identify all coefficients associated with the distressed firms. However, adding the distressed compliers to the ailing compliers, and the distressed violators to the ailing violators and running DIDID regression (6) excluding all variables involving Distressed, we find results identical to those shown in the paper. 
columns (2) and (5) significantly raise their risk after a strike, the ailing violators in columns (3) and (6) do not change or significantly decrease theirs. For example, while the coefficient on the triple interaction in the model explaining FirmRisk is 1.02 for the ailing compliers ( $p$-value: 0.007; see column (2)), the same coefficient is -2.16 for the ailing violators ( $p$-value: 0.006 ; column (3)). Thus, in line with Pryshchepa, Aretz, and Banerjee (2013), creditor control seems to prevent ailing or distressed firms from taking on more risk due to high distress risk. Also, since the response of the ailing violators reflects creditors' optimal response to a hurricane strike, the risk-taking of the ailing compliers is unlikely to be in creditors' interest.

Overall, our evidence thus not only suggests that ailing firms raise their risk in response to a hurricane strike, but also that they do so through making value-reducing investments significantly boosting their failure risk and lowering the chance that they can repay their creditors in the future. Conversely, if anything, distressed firms decrease their risk through making value-enhancing investments not altering their failure risk in the same situation. More directly indicating that the ailing firms' behavior is suboptimal for their creditors, our evidence also suggests that ailing firms controlled by creditors do not change or even decrease their risk after a strike, while ailing firms still acting in shareholders' interest raise their risk.

\section{Robustness Tests}

In this section, we show the results of robustness tests. We start with parallel trends tests. We next rerun DIDID regression (6) using alternatively calculated risk proxies. We then show that hurricane strikes do not systematically distort the volatilities of the pure-play firm industry portfolios. We also offer evidence suggesting that our result that ailing firms risk-shift in response to a hurricane strike is driven by those ailing firms not insured against hurricane strikes. We finally calculate bootstrap $p$-values for the triple interactions involving Ailing and Distressed in the DIDID regressions explaining FirmRisk and InvestmentRisk. 


\subsection{Parallel Trends Tests}

Differences tests rely on the assumption that subjects are randomly assigned to treatment. To test this assumption, Table 9 compares changes in several analysis variables between hurricanestruck vs. non-hurricane-struck firms (Panel A), ailing vs. healthy firms (Panel B), and distressed vs. healthy firms (Panel C) over two pre-hurricane periods. The analysis variables are FirmRisk, InvestmentRisk, DistressRisk, BookToMarket, Capex, and PPEEE. The pre-hurricane periods are the two-year and five-year periods before the hurricane-strike year. The table suggests that neither pair observes significantly different changes in the analysis variables. For example, hurricane-struck and non-hurricane-struck firms observe similar changes in FirmRisk and InvestmentRisk over the two periods, with no difference being significant. So do the healthy and ailing — or, alternatively, distressed — firms, except that distressed firms observe slightly larger increases in FirmRisk than healthy firms over the two-year period. ${ }^{26}$

\section{TABLE 9 ABOUT HERE}

Despite the parallel-trends test results, there could still be concern that the healthy, ailing, and distressed firms differ along dimensions other than distress risk. To mitigate this concern, we have rerun our analyses on a PS-matched sample ensuring that the differently distressed firms do not differ across observables other than distress risk. We discuss the results from reestimating our regressions explaining FirmRisk and InvestmentRisk on the PS-matched sample in Section 5.3.b. and report them in Table 5. We offer the results from reestimating the other regressions on the PS-matched sample in the Internet Appendix. Reassuringly, the PS-matched sample consistently yields conclusions identical to those in the paper.

\footnotetext{
${ }^{26}$ We have also compared the industry compositions of the distress risk groups. Our evidence suggests that similar proportions of the healthy, ailing, and distressed firms belong to each one-digit SIC industry. For example, $42.3 \%(42.5 \%)$ [38.9\%] of the healthy (ailing) [distressed] firms are manufacturing firms. Differences in the proportions across the different distress risk groups are, in general, not significant.
} 


\subsection{Alternative Risk Proxies}

In this section, we use alternative versions of our risk proxies to reassess whether firms raise their risk after a hurricane strike, reporting the results from reestimating DIDID regression (6) on the alternative versions of the risk proxies in Table 10. A concern with our first risk proxy, FirmRisk, is that it uses a segment's book value of assets to determine the segment's weight in an operating segment portfolio. This may be problematic since the book value of assets does not only change with managerial decisions, but also due to accounting rules. Accounting rules, for example, mandate that a segment's profit over a fiscal year is added to its book value of assets at the end of the year. To mitigate this concern, we have recalculated FirmRisk using a segment's sales, recognizing that sales values are less affected by accounting rules than asset values. Using this alterative version of FirmRisk in DIDID regression (6), column (1) of Table 10 suggests that ailing firms still significantly raise their firm risk after a hurricane strike, while distressed firms still significantly decrease theirs ( $p$-values: 0.005 and 0.027 , respectively).

\section{TABLE 10 ABOUT HERE}

A second concern is that financial leverage may vary significantly across the pure-play firm industries, spuriously raising our estimates of the asset volatilities of high-leverage industries relative to those of low-leverage industries. To mitigate this concern, we have recalculated the volatilities and covariances of the pure-play firm industry portfolios from delevered stock returns, using the Merton (1974) model to delever stock returns. ${ }^{27}$ Using versions of FirmRisk and InvestmentRisk derived from the delevered industry portfolio returns in DIDID regression (6), columns (2) and (3) continue to suggest that ailing firms significantly raise their firm- and investment-risk after a hurricane strike ( $p$-values: 0.051 and 0.034, respectively), while

\footnotetext{
${ }^{27}$ Merton's (1974) model suggests that we are able to calculate delevered stock returns using $\left(E_{i, t} / A_{i, t}\right) \times$ $\left(1 / N\left[d_{1 ; i, t}\right]\right) \times r_{E, i}$, where $r_{E, i}$ is firm $i$ 's stock return and other variables are defined as before.
} 
distressed firms significantly lower theirs ( $p$-values: 0.007 and 0.020, respectively).

A final concern is that a firm's segment holdings must have a higher volatility than a welldiversified portfolio of pure-play firms operating in the segment's industry since the firm does not benefit from diversification. To address this concern, we have recalculated the volatilities of the pure-play firm industry portfolios as value-weighted averages of the volatilities of the firms in the portfolios. Doing so, we effectively assume that the stock returns of all firms in a pure-play firm industry portfolio are perfectly positively correlated, eliminating diversification benefits. Using versions of FirmRisk and InvestmentRisk net of diversification benefits in DIDID regression (6), columns (4) and (5) continue to suggest that ailing firms significantly raise their risks after a hurricane strike ( $p$-values: 0.051 and 0.017 , respectively), while distressed firms sometimes significantly lower theirs ( $p$-values: 0.026 and 0.160 , respectively).

\subsection{The Effect of Hurricane Strikes on Segment Volatilities}

In this section, we investigate the concern that our tests only spuriously suggest that hurricane strikes prompt ailing firms to take on more risk because hurricane strikes change the variancecovariance matrix of the pure-play firm industry portfolios. If hurricane strikes, for example, transformed pre-hurricane-strike high-risk industries into post-hurricane-strike low-risk industries, and vice versa, the ailing firms would actually decrease their risk in response to a hurricane strike, and not increase it. To alleviate this concern, we form pure-play firm industry portfolios using only pure-play firms located in hurricane-struck areas over a hurricane's event period. In the Internet Appendix, we then offer the results from various tests, including the Friedman (1937) test, suggesting that the ranking of the industries according to their volatilities does not significantly change from the pre- to the post-hurricane period. 


\subsection{The Effect of Hurricane Strike Insurance}

In this section, we offer evidence that our main conclusions continue to hold if we eliminate firms possibly insured against hurricane strikes from our analysis. To do so, we split the hurricanestruck firms into those that received at least one positive settlement payment (Compustat item: setp) over the two or ten years after a hurricane strike and those that did not. Given that settlement payments include non-insurance-related payments, we cannot be reasonable sure that the firms that received at least one positive payment were insured. In contrast, we can, however, be reasonably sure that the firms that never received a positive payment were uninsured. Rerunning DIDID regression (6) on the subsample of uninsured firms, our results again suggest that ailing, but not distressed, firms raise their firm- and investment-risk in response to a hurricane strike. The details are in the Internet Appendix.

\subsection{Bootstrap Tests}

We finally conduct a bootstrap experiment, with the dual purpose of verifying our asymptotic inferences, but also as falsification test. To do so, we randomly reshuffle the identity of the treated (hurricane-struck) firms across the full sample of treated firms and matched controls per hurricane season. For example, if there are 22 treated firms and 187 controls in a hurricane season, we first pool the firms and then randomly assign treatment status to 22 , with each firm being equally likely to be assigned. Using the bootstrapped version of Treated, we next repeat DIDID regression (6) on either FirmRisk or InvestmentRisk. We repeat these steps 10,000 times, each time recording the coefficients on the triple interactions.

Figure 5 shows the bootstrap distributions for the coefficients on the triple interactions involving Ailing (Panel A) and Distressed (Panel B) from the DIDID regression explaining FirmRisk (columns (1) to (3) in Table 4). Panel A suggests that a coefficient on the triple interaction involving Ailing of 0.86 is unlikely to occur under the null hypothesis since only

$3.3 \%$ of the bootstrapped coefficients are more extreme than 0.86. Conversely, Panel B suggests 

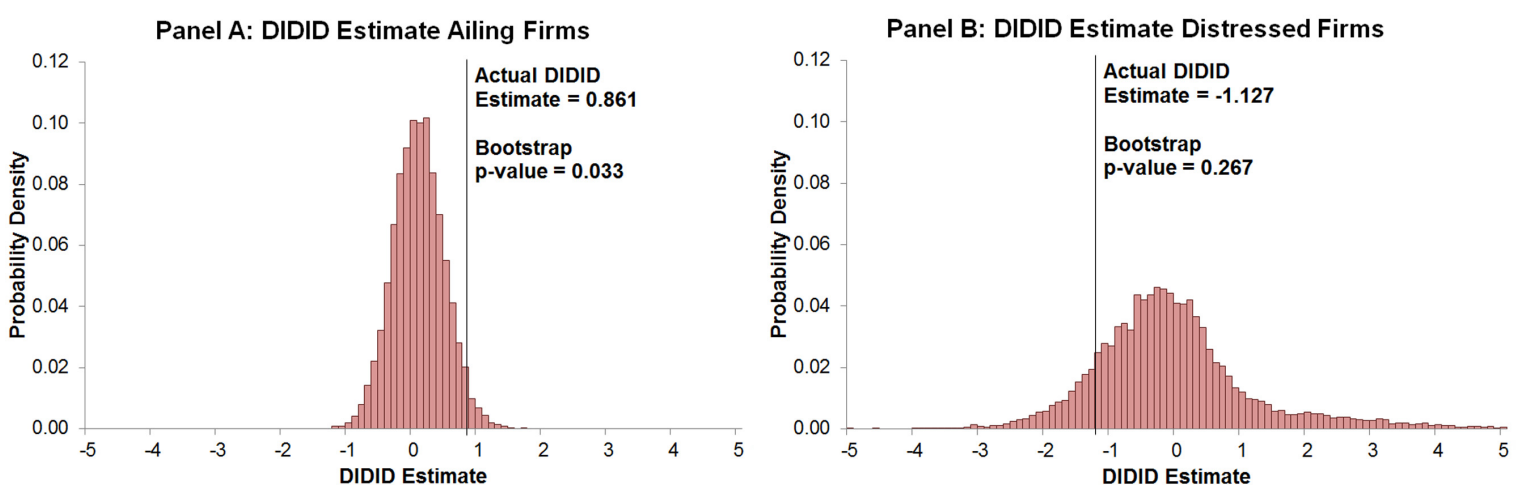

Figure 5. Bootstrap Tests The figure shows the bootstrap distributions for the coefficients on the triple interactions involving Ailing (Panel A) and Distressed (Panel B) from DIDID regression (6) explaining FirmRisk. We create the bootstrap distributions from 10,000 bootstrap experiments, with each experiment randomly reshuffling the identity of the hurricane-struck firms per hurricane season.

that a coefficient on the triple interaction involving Distressed of -1.13 is not unlikely to occur since $26.7 \%$ of the bootstrapped coefficients are more extreme than -1.13 . While not shown, the corresponding percentages from the DIDID regression explaining InvestmentRisk (columns (4) to (6) in Table 4) are $0.40 \%$ and $57.8 \%$, respectively. The bootstrap thus confirms that only ailing, but not distressed firms, take on more risk after a hurricane strike.

We have also calculated bootstrap inferences for the coefficients on the triple interactions in the DIDID regressions in Tables 5, 6, 7, and 8. In general, the bootstrap inferences align with our parametric inferences. The only exception is the coefficient on the tripe interaction involving Ailing in the model explaining Cash (column (4) in Table 6), which is no longer significant at conventional confidence levels using the bootstrap inferences.

\section{Conclusion}

We study whether industrial firms raise their risk in response to exogenous distress risk increases induced through hurricane strikes. Using two new risk proxies reflecting deliberate managerial decisions to change the risk of a firm's operating segment portfolio or of its new real-assets portfolio in differences tests, we offer evidence that only ailing, but not distressed, firms take on more risk in such situations. Studying how the ailing firms take on more risk, we find 
that they reorientate themselves towards their higher-risk segments, closing down lower-risk segments in the process. Looking at real consequences, we show that the ailing firms take on more risk by making value-reducing and failure-risk-increasing investments into segments with few growth opportunities. We also contrast the ailing firms' response to a hurricane strike with the response of distressed firms, showing, first, that distressed, but not ailing, firms are often under creditor control induced through covenant violations and, second, that only covenant compliers, and not covenant violators, raise their risk after a hurricane strike. While other studies have already shown that exogenous increases in distress risk can lead industrial firms to raise their risk, our evidence is important since it not only implies that some firms raise their risk in such situations, but also that they hurt their creditors in doing so. Thus, we do not only offer positive evidence of risk-taking, but, ultimately, of risk-shifting. 


\section{References}

Acharya, V. V., Amihud, Y., and Litov, L. (2011) Creditor rights and corporate risk-taking, Journal of Financial Economics 102, 150-166.

Andrade, G., and Kaplan, S. N. (1998) How costly is financial (not economic) distress? Evidence from highly leveraged transactions that became distressed, Journal of Finance $53,1443-1493$.

Aretz, K., Florackis, C., and Kostakis, A. (2017) Do stock returns really decrease with default risk? New international evidence, Forthcoming in Management Science.

Armstrong, C. S., and Vashishtha, R. (2012) Executive stock options, differential risk-taking incentives, and firm value, Journal of Financial Economics 104, 70-88.

Basak, S., Pavlova, A., and Shapiro, A. (2007) Optimal asset allocation and risk shifting in money management, Review of Financial Studies 20, 1583-1621.

Becker, B., and Strömberg, P. (2012) Fiduciary duties and equity-debtholder conflicts, Review of Financial Studies 25, 1931-1969.

Bertrand, M., Duflo, E., and Mullainathan, S. (2004) How much should we trust differencesin-differences estimates?, Quarterly Journal of Economics 119, 249-275.

Bertrand, M., and Mullainathan, S. (2003) Enjoying the quiet life? Corporate governance and managerial preferences, Journal of Political Economy 111, 1043-1075.

Black, F., and Scholes, M. S. (1973) The pricing of options and corporate liabilities, Journal of Political Economy 81, 637-659.

Blake, E. S., Landsea, C. W., and Gibney, E. J. (2011) The deadliest, costliest, and most intense United States hurricanes from 1851 to 2010 (and other frequently requested hurricane facts), National Weather Service. NOAA Technical Memorandum NWS NHC-6.

Brealey, R. A., Myers, S. C., and Allen, F. (2014) Principles of Corporate Finance, McGraw Hill Higher Education, Boston, Massachusetts.

Brown, K. C., Harlow, W. V., and Starks, L. T. (1996) Of tournaments and temptations: An analysis of managerial incentives in the mutual fund industry, Journal of Finance 51, $85-110$.

Brown, S. J., Goetzmann, W. N., and Park, J. (2001) Careers and survival: Competition and risk in the hedge fund and CTA industry, Journal of Finance 56, 1869-1886.

Campbell, T. S., and Kracaw, W. A. (1990) Corporate risk management and the incentive effects of debt, Journal of Finance 45, 1673-1686.

Chava, S., and Roberts, M. R. (2008) How does financing impact investment? The role of debt covenants, Journal of Finance 63, 2085-2121. 
Chen, Z., Strebulaev, I. A., Xing, Y., and Zhang, X. (2014) Strategic risk shifting and the idiosyncratic volatility puzzle, Working Paper.

Coles, J. L., Daniel, N. D., and Naveen, L. (2006) Managerial incentives and risk-taking, Journal of Financial Economics 79, 431-468.

Coval, J. D., and Moskowitz, T. J. (1999) Home bias at home: Local equity preference in domestic portfolios, Journal of Finance 54, 2045-2073.

Dailey, P. S., Zuba, G., Greta, L., Dima, I. M., and Guin, J. (2009) On the relationship between North Atlantic Sea surface temperatures and U.S. hurricane landfall risk, Journal of Applied Meterology and Climatology 48, 111-129.

Datta, S., D’Mello, R., and Iskandar-Datta, M. (2009) The information content of bankruptcy filing on securityholders of the bankrupt firm: An empirical investigation, Journal of Financial Intermediation 18, 242-258.

DeJong, A., and VanDijk, R. (2007) Determinants of leverage and agency problems: A regression approach with survey data, European Journal of Finance 13, 565-593.

Dessaint, O., and Matray, A. (2017) Do managers overreact to salient risks? Evidence from hurricane strikes, Journal of Financial Economics 126, 97-121.

Dittmar, A., and Shivdasani, A. (2003) Divestitures and divisional investment policies, Journal of Finance 58, 2711-2744.

Eisdorfer, A. (2008) Empirical evidence of risk shifting in financially distressed firms, Journal of Finance 63, 609-637.

Emanuel, K., and Zhang, F. (2016) On the predictability and error sources of tropical cyclone intensity forecasts, Journal of the Atmospheric Sciences 73, 3739-3747.

Esty, B. C. (1997a) Organizational form and risk taking in the savings and loan industry, Journal of Financial Economics 44, 25-55.

Esty, B. C. (1997b) A case study of organizational form and risk shifting in the savings and loan industry, Journal of Financial Economics 44, 57-76.

Fang, M., and Zhong, R. (2004) Default risk, firm's characteristics, and risk shifting, Working Paper.

Favara, G., Morellec, E., Schroth, E., and Valta, P. (2017) Debt enforcement, investment, and risk-taking across countries, Journal of Financial Economics 23, 22-41.

Friedman, M. (1937) The use of ranks to avoid the assumption of normality implicit in the analysis of variance, Journal of the American Statistical Association 32, 675-701.

Froot, K. A. (2001) The market for catastrophe risk: A clinical examination, Journal of Financial Economics 60, 529-571. 
Garmaise, M. J., and Moskowitz, T. J. (2009) Catastrophic risk and credit markets, Journal of Finance 64, 657-707.

Gavish, B., and Kalay, A. (1983) On the asset substitution problem, Journal of Financial and Quantitative Analysis 60, 187-243.

Gilje, E. (2016) Do firms engage in risk shifting? Empirical evidence. Review of Financial Studies 29, 2925-2954.

Gopalan, R., and Xie, K. (2011) Conglomerates and industry distress, Review of Financial Studies 24, 3642-3687.

Graham, J. R., and Harvey, C. (2001) The theory and practice of corporate finance: Evidence from the field, Journal of Financial Economics 60, 187-243.

Green, R. C. (1984) Investment incentives, debt, and warrants, Journal of Financial Economics $13,115-136$.

Green, R. C., and Talmor, E. (1986) Asset substitution and the agency costs of debt financing, Journal of Banking and Finance 10, 391-399.

Henry, D. K., Cooke-Hull, S., Savukinas, J., Yu, F., Elo, N., and Van Arnum, B. (2013) Economic impact of Hurricane Sandy: Potential economic activity lost and gained in New Jersey and New York. U.S. Department of Commerce Report.

Himmelberg, C. P., Hubbard, G., and Palia, D. (1999) Understanding the determinants of managerial ownership and the link between ownership and performance, Journal of Financial Economics 53, 353-384.

Hsiang, S. M., and Jian, A. S. (2014) The causal effect of environmental catastrophe on long-run economic growth: Evidence from 6,700 cyclones, Working Paper.

Huang, J., Clemens, S., and Hanjiang, Z. (2011) Risk shifting and mutual fund performance, Review of Financial Studies 24, 2575-2616.

Jensen, M. C., and Meckling, W. H. (1976) Theory of the firm: Managerial behavior, agency costs and ownership structure, Journal of Financial Economics 3, 305-360.

Kini, O., and Williams, R. (2012) Tournament incentives, firm risk, and corporate policies, Journal of Financial Economics 103, 350-376.

Laeven, L., and Levine, R. (2009) Bank governance, regulation and risk taking, Journal of Financial Economics 93, 259-275.

Larsen, P. T. (2006) Default risk, debt maturity and levered equity's risk shifting incentives, Working paper.

Leland, H. E. (1998) Agency costs, risk management, and capital structure, Journal of Finance 53, 1213-1243. 
Low, A. (2009) Managerial risk-taking behavior and equity-based compensation, Journal of Financial Economics 92, 470-490.

Markowitz, H. (1952) Portfolio selection, Journal of Finance 7, 77-91.

Merton, R. C. (1974) On the pricing of corporate debt: The risk structure of interest rates, Journal of Finance 29, 449-470.

O'Doherty, N. A., and Smith, C. W. (1993) Corporate insurance strategy: The case of British Petroleum, Journal of Applied Corporate Finance 6, 4-15.

Pielke Jr, R., Wigley, T., and Green, C. (2008) Dangerous assumptions, Nature 452, 531-532.

Prinsky, C., and Wang, Q. (2006), Does corporate headquarters location matter for stock returns?, Journal of Finance 61, 1991-2015.

Pryshchepa, O., Aretz, K., and Banerjee, S. (2013) Can investors restrict managerial investment behavior in distressed firms?, Journal of Corporate Finance 23, 222-239.

Rajan, R., Servaes, H., and Zingales, L. (2000) The cost of diversity: The diversification discount and inefficient investment, Journal of Finance 55, 35-80.

Saunders, A., Strock, E., and Travlos, N. G. (1990) Ownership structure, deregulation, and bank risk taking, Journal of Finance 45, 643-654.

Shin, H., and Stulz, R. M. (1998) Are internal capital markets efficient? Quarterly Journal of Economics 113, 531-552.

Smith, C. W., and Warner, J. B. (1979) On financial contracting: An analysis of bond covenants, Journal of Financial Economics 2, 117-161.

Vassalou, M., and Xing, Y. (2004) Default risk in equity returns, Journal of Finance 59, 833-868.

White, H. (1980) A heteroskedasticity-consistent covariance matrix estimator and a direct test for heteroskedasticity, Econometrica 48, 817-838. 


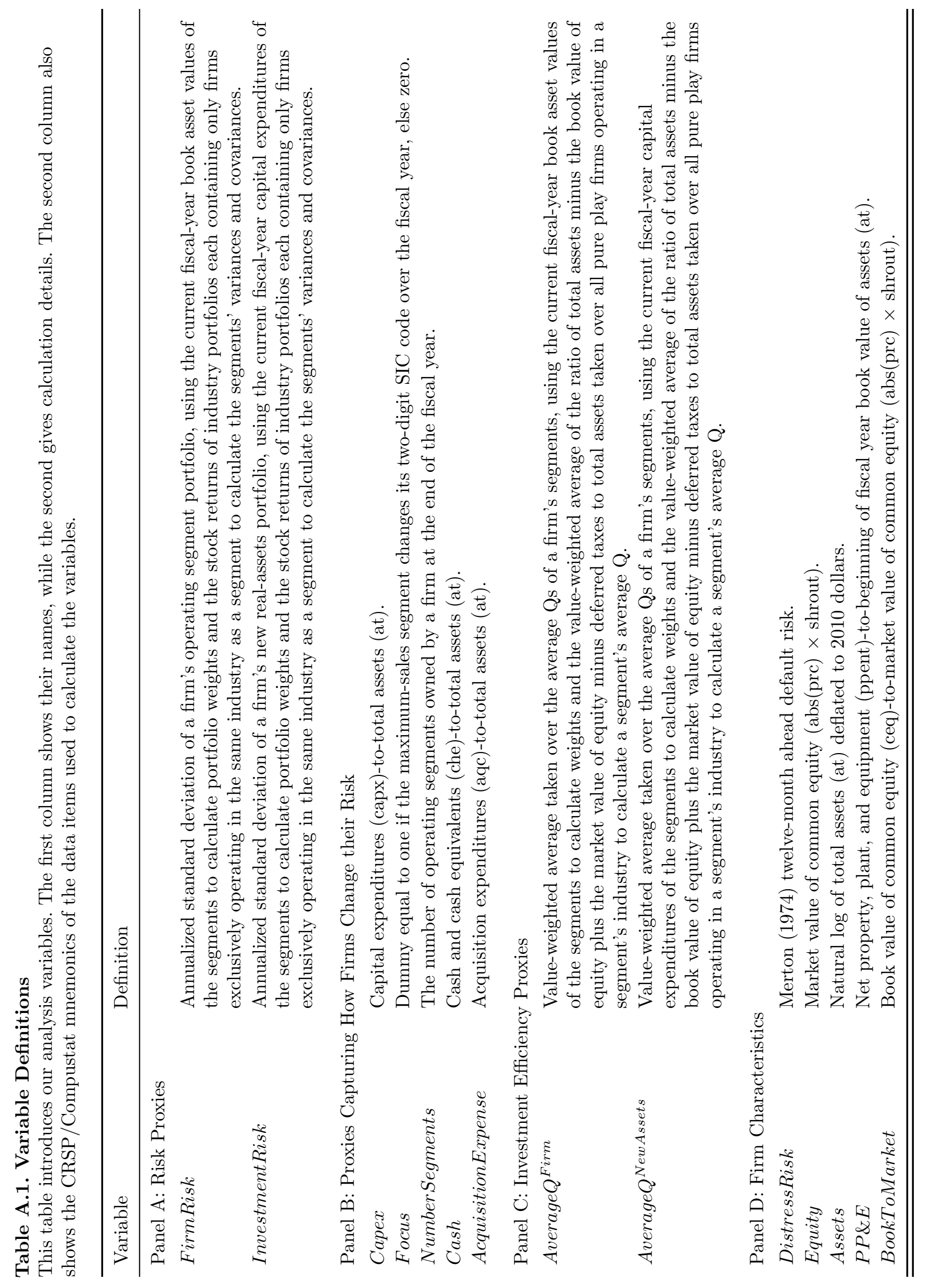




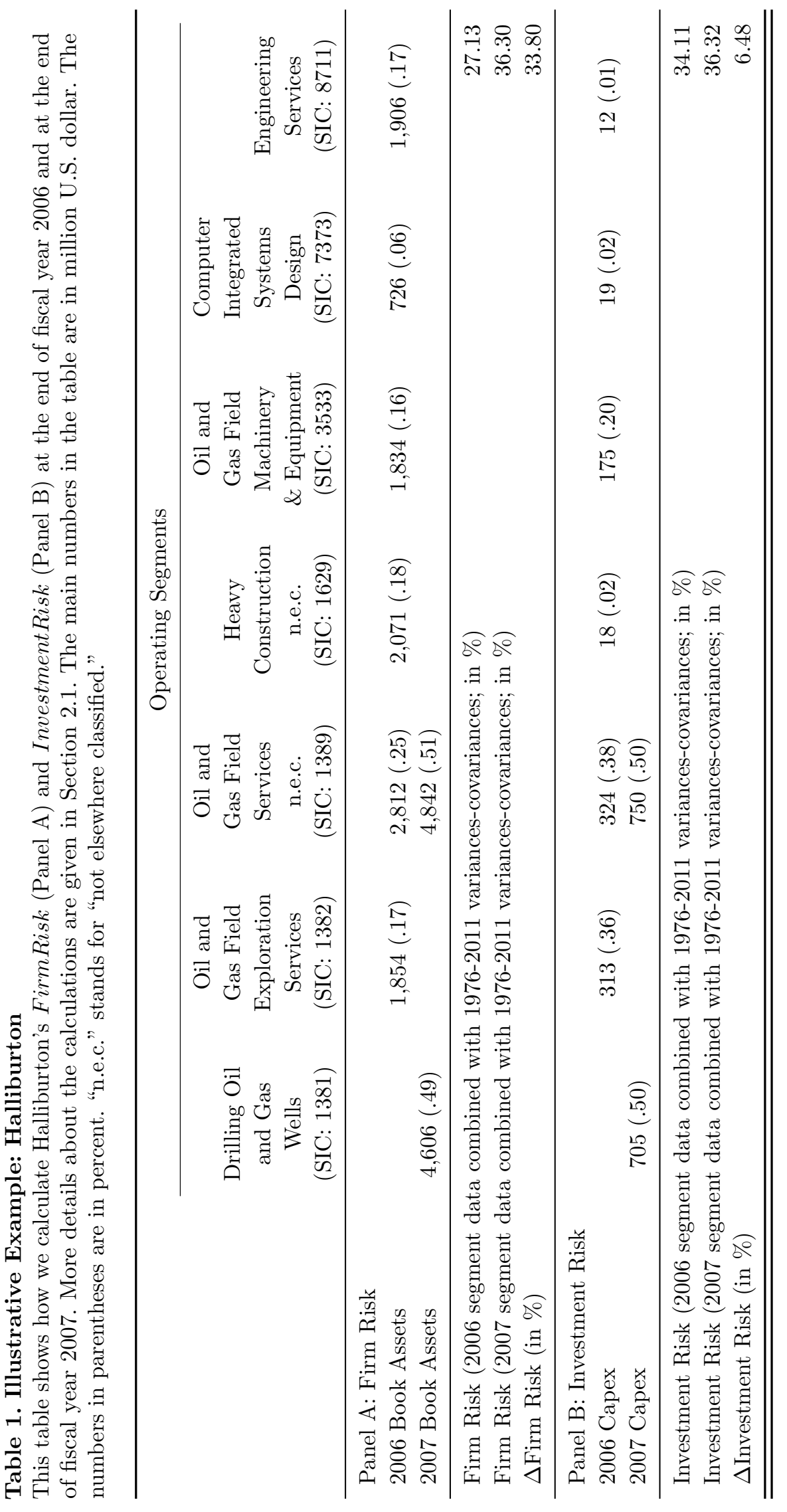




\section{Table 2. Descriptive Statistics}

This table presents descriptive statistics for our analysis variables, including the number of observations (Obs), the mean (Mean), the standard deviation (SD), the tenth (P10), 25th (P25), 50th (P50), 75th (P75), and 90th (P90) percentiles. In case of FirmRisk, InvestmentRisk, and DistressRisk, we report the descriptive statistics separately for the full sample ("Full"), the healthy-firm subsample ("Healthy"), the ailing-firm subsample ("Ailing"), and the distressed-firm subsample ("Distressed"). Healthy (ailing) [distressed] firms have a DistressRisk value below the sixth decile (between the sixth and the ninth deciles) [above the ninth decile] at the end of one of the fiscal years in our sample period. More details about the analysis variables are in Table A.1 in the Appendix. To ease interpretation, the table reports Assets and Equity in millions of U.S. dollars (and not logged).

\begin{tabular}{lcrrrrrrrr}
\hline & Sample & Obs & Mean & \multicolumn{1}{c}{ SD } & \multicolumn{1}{c}{ P10 } & P25 & \multicolumn{1}{c}{ P50 } & P75 & P90 \\
\hline FirmRisk (\%) & Full & 18,702 & 29.70 & 5.77 & 22.81 & 25.91 & 29.11 & 33.39 & 37.91 \\
& Healthy & 10,429 & 29.27 & 5.72 & 22.51 & 25.48 & 28.63 & 33.14 & 37.21 \\
& Ailing & 6,653 & 30.09 & 5.68 & 23.30 & 26.24 & 29.59 & 33.70 & 38.14 \\
& Distressed & 1,620 & 30.85 & 6.22 & 23.50 & 26.50 & 30.57 & 34.88 & 39.02 \\
InvestmentRisk(\%) & Full & 17,155 & 29.95 & 5.85 & 22.98 & 26.11 & 29.35 & 33.70 & 38.28 \\
& Healthy & 9,599 & 29.47 & 5.77 & 22.54 & 25.66 & 28.71 & 33.39 & 37.62 \\
& Ailing & 6,076 & 30.37 & 5.78 & 23.32 & 26.30 & 30.00 & 34.02 & 38.54 \\
& Distressed & 1,480 & 31.36 & 6.24 & 23.77 & 26.97 & 31.01 & 35.54 & 39.40 \\
DistressRisk(\%) & Full & 18,702 & 6.73 & 18.43 & 0.00 & 0.00 & 0.00 & 0.65 & 22.99 \\
& Healthy & 10,429 & 0.01 & 0.07 & 0.00 & 0.00 & 0.00 & 0.00 & 0.00 \\
& Ailing & 6,653 & 5.90 & 11.92 & 0.00 & 0.01 & 0.37 & 5.65 & 20.22 \\
Equity (MLN\$) & Distressed & 1,620 & 53.43 & 29.39 & 9.42 & 30.31 & 55.51 & 78.68 & 92.93 \\
Assets (MLN\$) & Full & 18,702 & 1,689 & 4,382 & 15 & 48 & 203 & 1,036 & 3,950 \\
PP\&E & Full & 18,702 & 1,982 & 5,515 & 20 & 56 & 251 & 1,189 & 4,352 \\
BookToMarket & Full & 18,702 & 0.295 & 0.256 & 0.048 & 0.109 & 0.224 & 0.405 & 0.645 \\
\hline \hline
\end{tabular}




\section{Table 3. The Effect of Distress Risk on Risk-Taking: ANOVA Tests}

This table presents the averages of FirmRisk (Panel A) and InvestmentRisk (Panel B) separately by distress risk group, hurricane-struck or non-hurricane-struck firms, and the pre-hurricane or post-hurricane period. We use distress risk values from the end of the fiscal year before the hurricane strike to sort firms into portfolios: "Healthy" contains those firms with a distress risk value below the sixth decile, "Ailing" those firms with a distress risk value between the sixth and the ninth decile, and "Distressed" those firms with a distress risk value above the ninth decile. The hurricane-struck firms are those located in a hurricane-struck county over the period in which the hurricane struck the county ("struck"); the matched control firms are those located in a non-hurricane-struck county over matched periods ("controls"). "Before strike ( -2 to -1$)$ " reports the average of the risk proxies taken over the ends of the two fiscal years before a hurricane-strike year, "After strike $(+1$ to +2$)$ " over the ends of the two fiscal years after. The table also reports the difference in the risk proxies between the three different distress risk groups (Differences) and the changes in the risk proxies from before a strike to after (After-Before). "***", “**", and "**" indicate significance at the $99 \%, 95 \%$, and $90 \%$ confidence levels, respectively.

\begin{tabular}{|c|c|c|c|c|c|c|}
\hline & \multirow[b]{2}{*}{$\begin{array}{c}\text { Hurricane } \\
\text { Struck }\end{array}$} & \multicolumn{3}{|c|}{ Distress Risk Groups } & \multicolumn{2}{|c|}{ Differences } \\
\hline & & $\begin{array}{c}\text { Healthy } \\
\text { (1) }\end{array}$ & $\begin{array}{l}\text { Ailing } \\
(2)\end{array}$ & $\begin{array}{c}\text { Distressed } \\
\quad(3)\end{array}$ & $(2)-(1)$ & $(3)-(1)$ \\
\hline \multicolumn{7}{|l|}{ Panel A: Firm Risk } \\
\hline \multirow{2}{*}{ Before Strike $(-2$ to -1$)$} & Struck & 30.16 & 28.46 & 30.42 & & \\
\hline & Controls & 29.14 & 30.09 & 31.10 & & \\
\hline \multirow[t]{2}{*}{ After Strike $(+1$ to +2$)$} & Struck & 30.41 & 29.63 & 30.12 & & \\
\hline & Controls & 29.32 & 30.31 & 31.46 & & \\
\hline \multirow[t]{2}{*}{ After-Before } & Struck & 0.25 & $1.17^{* *}$ & -0.31 & $0.92^{*}$ & -0.56 \\
\hline & Controls & $0.18^{* * *}$ & $0.22^{* * *}$ & $0.37^{* *}$ & 0.04 & 0.18 \\
\hline \multicolumn{7}{|l|}{ Panel B: Investment Risk } \\
\hline \multirow[t]{2}{*}{ Before Strike $(-2$ to -1$)$} & Struck & 30.63 & 28.78 & 31.27 & & \\
\hline & Controls & 29.34 & 30.32 & 31.50 & & \\
\hline \multirow[t]{2}{*}{ After Strike $(+1$ to +2$)$} & Struck & 30.68 & 29.98 & 31.13 & & \\
\hline & Controls & 29.51 & 30.50 & 31.99 & & \\
\hline \multirow[t]{2}{*}{ After-Before } & Struck & 0.05 & $1.20^{* * *}$ & -0.13 & $1.15^{* *}$ & -0.19 \\
\hline & Controls & $0.17^{* * *}$ & $0.17^{* * *}$ & $0.49^{* *}$ & 0.00 & 0.31 \\
\hline
\end{tabular}


Table 4. The Effect of Distress Risk on Risk-Taking: Regression Results

This table presents the results from the DIDID regression:

$$
\begin{aligned}
\text { RiskProxy }_{i, t} & =\alpha_{i, k}+\alpha_{t, k}+\boldsymbol{\beta}^{\prime} \text { Distress }_{i, t} \times \text { Treated }_{i, t} \times \text { After }_{i, t}+\boldsymbol{\gamma}^{\prime} \text { Distress }_{i, t} \times \text { Treated }_{i, t} \\
& +\boldsymbol{\delta}^{\prime} \text { Distress }_{i, t} \times \text { After }_{i, t}+\boldsymbol{\eta}^{\prime} \text { Distress }_{i, t} \otimes \mathbf{X}_{i, t}+\varepsilon_{i, t}
\end{aligned}
$$

where RiskProxy is FirmRisk in columns (1) to (3), and InvestmentRisk in columns (4) to (6). Treated is a dummy variable equal to one for firm-year observations associated with firms located in a hurricane-struck county over the five year-period surrounding a hurricane strike and zero for matched control firm-year observations. After is a dummy variable equal to one for treated and matched firm-year observations after a hurricane strike and else zero. $\mathbf{X}$ is a vector of control variables, including Assets, $P P \mathscr{E} E$, and $P P \mathscr{E} E^{2}$. We sort firms into distress risk portfolios using DistressRisk at the end of the fiscal year before a hurricane strike: Healthy firms have a distress risk value below the sixth decile; ailing firms have a distress risk value between the sixth and the ninth decile; and distressed firms have a distress risk value above the ninth decile. Distress ${ }_{i, t}$ is a vector containing one, a dummy variable equal to one for ailing firms and else zero (Ailing), and a dummy variable equal to one for distressed firms and else zero (Distressed). $\alpha_{i, k}$ and $\alpha_{t, k}$ are firm-distress portfolio- and year-distress portfolio-fixed effects. $\boldsymbol{\beta}, \boldsymbol{\gamma}$, $\boldsymbol{\delta}$, and $\boldsymbol{\eta}$ are free parameters. More details about the analysis variables are in Table A.1 in the Appendix. For each firm, we include the two observations before a hurricane strike and the two after. The table shows parameter estimates and standard errors (in parentheses). Standard errors are calculated from White's (1980) formula. "***",

\begin{tabular}{|c|c|c|c|c|c|c|}
\hline & \multicolumn{6}{|c|}{ Dependent Variable } \\
\hline & \multicolumn{3}{|c|}{ Firm Risk } & \multicolumn{3}{|c|}{ Investment Risk } \\
\hline & \multicolumn{6}{|c|}{ Independent Variable Interacted With } \\
\hline & One & $\begin{array}{c}\text { Ailing } \\
\text { Dummy }\end{array}$ & $\begin{array}{l}\text { Distressed } \\
\text { Dummy }\end{array}$ & One & $\begin{array}{l}\text { Ailing } \\
\text { Dummy }\end{array}$ & $\begin{array}{c}\text { Distressed } \\
\text { Dummy }\end{array}$ \\
\hline & (1) & $(2)$ & $(3)$ & (4) & $(5)$ & $(6)$ \\
\hline Treated $\times$ After & $\begin{array}{r}0.084 \\
(0.151)\end{array}$ & $\begin{array}{c}0.861^{* *} \\
(0.365)\end{array}$ & $\begin{array}{l}-1.127^{* *} \\
(0.548)\end{array}$ & $\begin{array}{l}-0.062 \\
(0.184)\end{array}$ & $\begin{array}{l}1.243^{* * *} \\
(0.410)\end{array}$ & $\begin{array}{l}-0.583 \\
(0.686)\end{array}$ \\
\hline Treated & $\begin{array}{l}-0.081 \\
(0.295)\end{array}$ & $\begin{array}{l}-1.797^{* *} \\
(0.793)\end{array}$ & $\begin{array}{l}-0.261 \\
(1.199)\end{array}$ & $\begin{array}{l}-0.029 \\
(0.325)\end{array}$ & $\begin{array}{l}-2.579^{* * *} \\
(0.898)\end{array}$ & $\begin{array}{l}-0.858 \\
(1.821)\end{array}$ \\
\hline After & $\begin{array}{l}-0.028 \\
(0.031)\end{array}$ & $\begin{array}{r}0.006 \\
(0.055)\end{array}$ & $\begin{array}{c}0.749^{* * *} \\
(0.246)\end{array}$ & $\begin{array}{r}0.000 \\
(0.033)\end{array}$ & $\begin{array}{l}-0.017 \\
(0.061)\end{array}$ & $\begin{array}{l}0.794^{* * *} \\
(0.269)\end{array}$ \\
\hline Assets & $\begin{array}{l}-0.181^{* * *} \\
(0.046)\end{array}$ & $\begin{array}{r}0.016 \\
(0.086)\end{array}$ & $\begin{array}{l}-0.485 \\
(0.316)\end{array}$ & $\begin{array}{l}-0.193^{* * *} \\
(0.047)\end{array}$ & $\begin{array}{r}0.040 \\
(0.091)\end{array}$ & $\begin{array}{l}-0.686^{*} \\
(0.377)\end{array}$ \\
\hline$P P \& E$ & $\begin{array}{l}-1.388^{* * *} \\
(0.410)\end{array}$ & $\begin{array}{r}0.016 \\
(0.086)\end{array}$ & $\begin{array}{r}0.533 \\
(0.660)\end{array}$ & $\begin{array}{l}-1.762^{* * *} \\
(0.420)\end{array}$ & $\begin{array}{r}0.040 \\
(0.091)\end{array}$ & $\begin{array}{r}0.170 \\
(0.705)\end{array}$ \\
\hline$P P \& E^{2}$ & $\begin{array}{l}1.161^{* * *} \\
(0.305)\end{array}$ & $\begin{array}{l}-0.658 \\
(0.459) \\
\end{array}$ & $\begin{array}{r}0.370 \\
(1.144)\end{array}$ & $\begin{array}{l}1.27^{* * *} \\
(0.322)\end{array}$ & $\begin{array}{l}-0.242 \\
(0.493)\end{array}$ & $\begin{array}{r}0.057 \\
(1.214)\end{array}$ \\
\hline Observations & & 27,387 & & & 25,196 & \\
\hline Adjusted R-squared & & 0.892 & & & 0.885 & \\
\hline
\end{tabular}
"**", and "*" indicate statistical significance at the 99\%, 95\%, and 90\% levels, respectively. 
Table 5. The Effect of Distress Risk on Risk-Taking: PS-Matched Sample Regression Results This table presents the results from the DIDID regression:

$$
\begin{aligned}
\text { RiskProxy }_{i, t} & =\alpha_{i, k}+\alpha_{t, k}+\boldsymbol{\beta}^{\prime} \text { Distress }_{i, t} \times \text { Treated }_{i, t} \times \text { After }_{i, t}+\boldsymbol{\gamma}^{\prime} \text { Distress }_{i, t} \times \text { Treated }_{i, t} \\
& +\boldsymbol{\delta}^{\prime} \text { Distress }_{i, t} \times \text { After }_{i, t}+\boldsymbol{\eta}^{\prime} \text { Distress }_{i, t} \otimes \mathbf{X}_{i, t}+\varepsilon_{i, t}
\end{aligned}
$$

where RiskProxy is FirmRisk in columns (1) to (3), and InvestmentRisk in columns (4) to (6). Treated is a dummy variable equal to one for firm-year observations associated with firms located in a hurricane-struck county over the five year-period surrounding a hurricane strike and zero for matched control firm-year observations. After is a dummy variable equal to one for treated and matched firm-year observations after a hurricane strike and else zero. $\mathbf{X}$ is a vector of control variables, including Assets, $P P \mathscr{E} E$, and $P P \mathscr{E} E^{2}$. We sort firms into distress risk portfolios using DistressRisk at the end of the fiscal year before a hurricane strike: Healthy firms have a distress risk value below the sixth decile; ailing firms have a distress risk value between the sixth and the ninth decile; and distressed firms have a distress risk value above the ninth decile. Distress ${ }_{i, t}$ is a vector containing one, a dummy variable equal to one for ailing firms and else zero (Ailing), and a dummy variable equal to one for distressed firms and else zero (Distressed). $\alpha_{i, k}$ and $\alpha_{t, k}$ are firm-distress portfolio- and year-distress portfolio-fixed effects. $\boldsymbol{\beta}, \boldsymbol{\gamma}$, $\boldsymbol{\delta}$, and $\boldsymbol{\eta}$ are free parameters. More details about the analysis variables are in Table A.1 in the Appendix. We estimate the regressions on a propensity-score (PS) matched sample. To do so, we use a logit model to estimate the probability that a firm has a DistressRisk value above the sixth decile, using Assets, Age, and PPEE as covariates. The logit model is estimated separately by one-digit SIC industry, using only data from the fiscal year before the hurricane strikes. We next match each firm with a DistressRisk value above the sixth decile with that below-sixth-decile value firm with the closest fitted value and from the same one-digit SIC industry. For each firm, we include the two observations before a hurricane strike and the two after. The table shows parameter estimates and standard errors (in parentheses). Standard errors are calculated from White's (1980) formula. “***”, “**”,

\begin{tabular}{|c|c|c|c|c|c|c|}
\hline & \multicolumn{6}{|c|}{ Dependent Variable } \\
\hline & \multicolumn{3}{|c|}{ Firm Risk } & \multicolumn{3}{|c|}{ Investment Risk } \\
\hline & \multicolumn{6}{|c|}{ Independent Variable Interacted With } \\
\hline & One & $\begin{array}{c}\text { Ailing } \\
\text { Dummy }\end{array}$ & $\begin{array}{c}\text { Distressed } \\
\text { Dummy }\end{array}$ & One & $\begin{array}{c}\text { Ailing } \\
\text { Dummy }\end{array}$ & $\begin{array}{l}\text { Distressed } \\
\text { Dummy }\end{array}$ \\
\hline & $(1)$ & $(2)$ & $(3)$ & $(4)$ & $(5)$ & (6) \\
\hline Treated $\times$ After & $\begin{array}{r}0.153 \\
(0.270)\end{array}$ & $\begin{array}{c}1.287^{* *} \\
(0.514)\end{array}$ & $\begin{array}{l}-0.409 \\
(0.554)\end{array}$ & $\begin{array}{r}0.037 \\
(0.269)\end{array}$ & $\begin{array}{l}1.679^{* * *} \\
(0.524)\end{array}$ & $\begin{array}{l}-0.626 \\
(0.801)\end{array}$ \\
\hline Treated & $\begin{array}{r}1.251 \\
(1.011)\end{array}$ & $\begin{array}{l}-4.079^{* *} \\
(1.660)\end{array}$ & $\begin{array}{l}-0.777 \\
(1.492)\end{array}$ & $\begin{array}{r}1.024 \\
(1.153)\end{array}$ & $\begin{array}{l}-4.408^{* * *} \\
(1.707)\end{array}$ & $\begin{array}{l}-1.031 \\
(2.051)\end{array}$ \\
\hline After & $\begin{array}{c}-0.11^{*} \\
(0.058)\end{array}$ & $\begin{array}{r}0.090 \\
(0.074)\end{array}$ & $\begin{array}{c}0.283^{*} \\
(0.167)\end{array}$ & $\begin{array}{l}-0.099^{*} \\
(0.060)\end{array}$ & $\begin{array}{r}0.066 \\
(0.081)\end{array}$ & $\begin{array}{c}0.435^{* *} \\
(0.177)\end{array}$ \\
\hline Assets & $\begin{array}{l}-0.238^{* * *} \\
(0.089)\end{array}$ & $\begin{array}{r}0.063 \\
(0.121)\end{array}$ & $\begin{array}{c}1.804^{*} \\
(0.968)\end{array}$ & $\begin{array}{l}-0.377^{* * *} \\
(0.098)\end{array}$ & $\begin{array}{c}0.248^{*} \\
(0.132)\end{array}$ & $\begin{array}{c}-0.482 \\
(1.023)\end{array}$ \\
\hline$P P \& E$ & $\begin{array}{l}-2.895^{* * *} \\
(0.779)\end{array}$ & $\begin{array}{c}1.804^{*} \\
(0.968)\end{array}$ & $\begin{array}{r}1.492 \\
(1.862)\end{array}$ & $\begin{array}{l}-2.059^{* * *} \\
(0.777)\end{array}$ & $\begin{array}{c}-0.482 \\
(1.023)\end{array}$ & $\begin{array}{r}0.954 \\
(1.993)\end{array}$ \\
\hline$P P \& E^{2}$ & $\begin{array}{l}2.044^{* * *} \\
(0.575)\end{array}$ & $\begin{array}{l}-1.408^{* *} \\
(0.703)\end{array}$ & $\begin{array}{l}-0.885 \\
(1.507)\end{array}$ & $\begin{array}{l}1.622^{* * *} \\
(0.594)\end{array}$ & $\begin{array}{r}0.060 \\
(0.788)\end{array}$ & $\begin{array}{r}-0.422 \\
(1.599)\end{array}$ \\
\hline Observations & & 13,912 & & & 13,888 & \\
\hline Adjusted R-squared & & 0.893 & & & 0.877 & \\
\hline
\end{tabular}
and "*" indicate statistical significance at the $99 \%, 95 \%$, and $90 \%$ levels, respectively. 
Table 6. Risk-Taking Channels: Regression Results

This table presents the results from the DIDID regression:

$$
\begin{aligned}
\text { RiskChannel }_{i, t} & =\alpha_{i, k}+\alpha_{t, k}+\boldsymbol{\beta}^{\prime} \text { Distress }_{i, t} \times \text { Treated }_{i, t} \times \text { After }_{i, t}+\boldsymbol{\gamma}^{\prime} \text { Distress }_{i, t} \times \text { Treated }_{i, t} \\
& +\boldsymbol{\delta}^{\prime} \text { Distress }_{i, t} \times \text { After }_{i, t}+\boldsymbol{\eta}^{\prime} \text { Distress }_{i, t} \otimes \mathbf{X}_{i, t}+\varepsilon_{i, t},
\end{aligned}
$$

where RiskChannel is either Capex, Focus, NumberSegments, Cash, or AcquisitionExpense. Capex is capital expenditures scaled by total assets. Focus is a dummy variable equal to one if a firm's maximum-sales segment changes its two-digit SIC code over the current fiscal year, else zero. NumberSegments is the number of segments owned by a firm. Cash is cash and equivalents scaled by total assets. AcquisitionExpense is acquisition expenditures scaled by total assets. Treated is a dummy variable equal to one for firm-year observations associated with firms located in a hurricane-struck county over the five year-period surrounding a hurricane strike and zero for matched control firm-year observations. After is a dummy variable equal to one for treated and matched firm-year observations after a hurricane strike and else zero. $\mathbf{X}$ is a vector of control variables, including Assets, PPE E , and $P P \mathscr{E} E^{2}$. We sort firms into distress risk portfolios using DistressRisk at the end of the fiscal year before a hurricane strike: Healthy firms have a distress risk value below the sixth decile; ailing firms have a distress risk value between the sixth and the ninth decile; and distressed firms have a distress risk value above the ninth decile. Distress ${ }_{i, t}$ is a vector containing one, a dummy variable equal to one for ailing firms and else zero (Ailing), and a dummy variable equal to one for distressed firms and else zero (Distressed). $\alpha_{i, k}$ and $\alpha_{t, k}$ are firm-distress portfolio- and year-distress portfolio-fixed effects. $\boldsymbol{\beta}, \boldsymbol{\gamma}, \boldsymbol{\delta}$, and $\boldsymbol{\eta}$ are free parameters. More details about the analysis variables are in Table A.1 in the Appendix. For each firm, we include the two observations before a hurricane strike and the two after. The table shows parameter estimates and standard errors (in parentheses), suppressing, however, estimates and standard errors for the control variables in X. Standard errors are calculated from White's (1980) formula. "***", "**", and "** indicate statistical significance at the $99 \%, 95 \%$, and $90 \%$ levels, respectively.

\begin{tabular}{lccccc}
\hline & & & Number & \multicolumn{2}{c}{ Acquisition } \\
& Capex & Focus & Segments & Cash & Expense \\
\hline Treated $\times$ After $\times$ Ailing & $(1)$ & $(2)$ & $(3)$ & $(4)$ & $(5)$ \\
Treated $\times$ After $\times$ Distressed & $0.023^{* *}$ & $0.117^{* *}$ & $-0.210^{* *}$ & 0.000 & -0.014 \\
& $(0.011)$ & $(0.055)$ & $(0.088)$ & $(0.021)$ & $(0.058)$ \\
Treated $\times$ After & 0.027 & $0.290^{* * *}$ & 0.126 & $-0.059^{* * *}$ & -0.028 \\
& $(0.017)$ & $(0.093)$ & $(0.184)$ & $(0.018)$ & $(0.046)$ \\
Treated $\times$ Ailing & $-0.018^{* * *}$ & $-0.058^{*}$ & 0.070 & 0.010 & 0.024 \\
Treated $\times$ Distressed & $(0.006)$ & $(0.034)$ & $(0.061)$ & $(0.011)$ & $(0.032)$ \\
After $\times$ Ailing & $-0.055^{* * *}$ & $-0.16^{*}$ & $-0.304^{*}$ & $0.052^{* *}$ & $0.145^{* *}$ \\
After $\times$ Distressed & $(0.019)$ & $(0.084)$ & $(0.178)$ & $(0.025)$ & $(0.062)$ \\
Treated & -0.009 & -0.383 & $-0.973^{* * *}$ & $0.139^{* * *}$ & 0.147 \\
& $(0.017)$ & $(0.499)$ & $(0.365)$ & $(0.041)$ & $(0.158)$ \\
After & 0.001 & -0.011 & 0.002 & $0.024^{* * *}$ & $-0.025^{* *}$ \\
& $(0.001)$ & $(0.010)$ & $(0.019)$ & $(0.004)$ & $(0.011)$ \\
Controls & $0.007^{* *}$ & 0.034 & $-0.086^{* * *}$ & $0.021^{* * *}$ & $-0.075^{* * *}$ \\
Observations & $(0.003)$ & $(0.021)$ & $(0.032)$ & $(0.008)$ & $(0.021)$ \\
Adjusted R-squared & $0.016^{*}$ & 0.042 & $0.238^{* *}$ & -0.006 & -0.041 \\
\hline \hline & $(0.009)$ & $(0.035)$ & $(0.108)$ & $(0.013)$ & $(0.031)$ \\
& $-0.002^{* * *}$ & -0.002 & 0.007 & $-0.012^{* * *}$ & 0.001 \\
& $(0.001)$ & $(0.006)$ & $(0.012)$ & $(0.002)$ & $(0.006)$ \\
\hline
\end{tabular}


Table 7. Investment Efficiency: Regression Results

This table presents the results from the DIDID regression:

$$
\begin{aligned}
\text { Average }_{i, t} & =\alpha_{i, k}+\alpha_{t, k}+\boldsymbol{\beta}^{\prime} \text { Distress }_{i, t} \times \text { Treated }_{i, t} \times \text { After }_{i, t}+\boldsymbol{\gamma}^{\prime} \text { Distress }_{i, t} \times \text { Treated }_{i, t} \\
& +\boldsymbol{\delta}^{\prime} \mathbf{D i s t r e s s}_{i, t} \times \text { After }_{i, t}+\boldsymbol{\eta}^{\prime} \mathbf{D i s t r e s s}_{i, t} \otimes \mathbf{X}_{i, t}+\varepsilon_{i, t},
\end{aligned}
$$

where AverageQ is Average $Q^{\text {Firm }}$ in columns (1) to (3), and Average $Q^{\text {NewAssets }}$ in columns (4) to (6). Treated is a dummy variable equal to one for firm-year observations associated with firms located in a hurricane-struck county over the five year-period surrounding a hurricane strike and zero for matched control firm-year observations. After is a dummy variable equal to one for treated and matched firm-year observations after a hurricane strike and else zero. $\mathbf{X}$ is a vector of control variables, including Assets, $P P \mathscr{E} E$, and $P P \mathscr{E} E^{2}$. We sort firms into distress risk portfolios using DistressRisk at the end of the fiscal year before a hurricane strike: Healthy firms have a distress risk value below the sixth decile; ailing firms have a distress risk value between the sixth and the ninth decile; and distressed firms have a distress risk value above the ninth decile. Distress ${ }_{i, t}$ is a vector containing one, a dummy variable equal to one for ailing firms and else zero (Ailing), and a dummy variable equal to one for distressed firms and else zero (Distressed). $\alpha_{i, k}$ and $\alpha_{t, k}$ are firm-distress portfolio- and year-distress portfolio-fixed effects. $\boldsymbol{\beta}, \boldsymbol{\gamma}$, $\boldsymbol{\delta}$, and $\boldsymbol{\eta}$ are free parameters. More details about the analysis variables are in Table A.1 in the Appendix. For each firm, we include the two observations before a hurricane strike and the two after. The table shows parameter estimates and standard errors (in parentheses). Standard errors are calculated from White's (1980) formula. "***",

\begin{tabular}{|c|c|c|c|c|c|c|}
\hline & \multicolumn{6}{|c|}{ Dependent Variable } \\
\hline & \multicolumn{3}{|c|}{ Average $\mathrm{Q}^{\text {Firm }}$} & \multicolumn{3}{|c|}{ Average $\mathrm{Q}^{\text {NewAssets }}$} \\
\hline & \multicolumn{6}{|c|}{ Independent Variable Interacted With } \\
\hline & One & $\begin{array}{l}\text { Ailing } \\
\text { Dummy }\end{array}$ & $\begin{array}{c}\text { Distressed } \\
\text { Dummy }\end{array}$ & One & $\begin{array}{c}\text { Ailing } \\
\text { Dummy }\end{array}$ & $\begin{array}{c}\text { Distressed } \\
\text { Dummy }\end{array}$ \\
\hline & (1) & (2) & (3) & (4) & (5) & (6) \\
\hline Treated $\times$ After & $\begin{array}{c}0.115^{*} \\
(0.065)\end{array}$ & $\begin{array}{l}-0.383^{\text {*** }} \\
(0.106)\end{array}$ & $\begin{array}{r}0.228 \\
(0.179)\end{array}$ & $\begin{array}{r}0.084 \\
(0.067)\end{array}$ & $\begin{array}{l}-0.326^{* * *} \\
(0.107)\end{array}$ & $\begin{array}{c}0.338^{*} \\
(0.189)\end{array}$ \\
\hline Treated & $\begin{array}{l}-0.016 \\
(0.083)\end{array}$ & $\begin{array}{r}0.047 \\
(0.118)\end{array}$ & $\begin{array}{r}0.000 \\
(0.000)\end{array}$ & $\begin{array}{l}-0.036 \\
(0.082)\end{array}$ & $\begin{array}{l}-0.022 \\
(0.120)\end{array}$ & $\begin{array}{r}0.000 \\
(0.000)\end{array}$ \\
\hline After & $\begin{array}{l}-0.031^{* * *} \\
(0.015)\end{array}$ & $\begin{array}{r}0.029 \\
(0.023)\end{array}$ & $\begin{array}{r}0.013 \\
(0.050)\end{array}$ & $\begin{array}{l}-0.038^{* *} \\
(0.016)\end{array}$ & $\begin{array}{r}0.038 \\
(0.025)\end{array}$ & $\begin{array}{r}0.051 \\
(0.063)\end{array}$ \\
\hline Assets & $\begin{array}{l}-0.103^{\text {*** }} \\
(0.019)\end{array}$ & $\begin{array}{r}0.037 \\
(0.030)\end{array}$ & $\begin{array}{r}0.044 \\
(0.048)\end{array}$ & $\begin{array}{l}-0.054^{* *} \\
(0.021)\end{array}$ & $\begin{array}{r}0.026 \\
(0.033)\end{array}$ & $\begin{array}{r}0.040 \\
(0.060)\end{array}$ \\
\hline$P P \& E$ & $\begin{array}{l}-0.294 \\
(0.181)\end{array}$ & $\begin{array}{c}0.792^{\text {*** }} \\
(0.246)\end{array}$ & $\begin{array}{c}0.78^{* *} \\
(0.317)\end{array}$ & $\begin{array}{l}-0.494^{* * *} \\
(0.192)\end{array}$ & $\begin{array}{c}0.844^{* * * *} \\
(0.264)\end{array}$ & $\begin{array}{c}0.827^{* *} \\
(0.339)\end{array}$ \\
\hline$P P \& E^{2}$ & $\begin{array}{c}0.322^{* * *} \\
(0.125)\end{array}$ & $\begin{array}{l}-0.572^{* * *} \\
(0.167)\end{array}$ & $\begin{array}{l}-0.503^{* *} \\
(0.210)\end{array}$ & $\begin{array}{c}0.44^{* * *} \\
(0.132)\end{array}$ & $\begin{array}{l}-0.655^{* * *} \\
(0.175)\end{array}$ & $\begin{array}{l}-0.514^{* *} \\
(0.218)\end{array}$ \\
\hline Observations & & 24,648 & & & 22,642 & \\
\hline Adjusted R-squared & & 0.587 & & & 0.572 & \\
\hline
\end{tabular}
"**", and "*" indicate statistical significance at the $99 \%, 95 \%$, and $90 \%$ levels, respectively. 


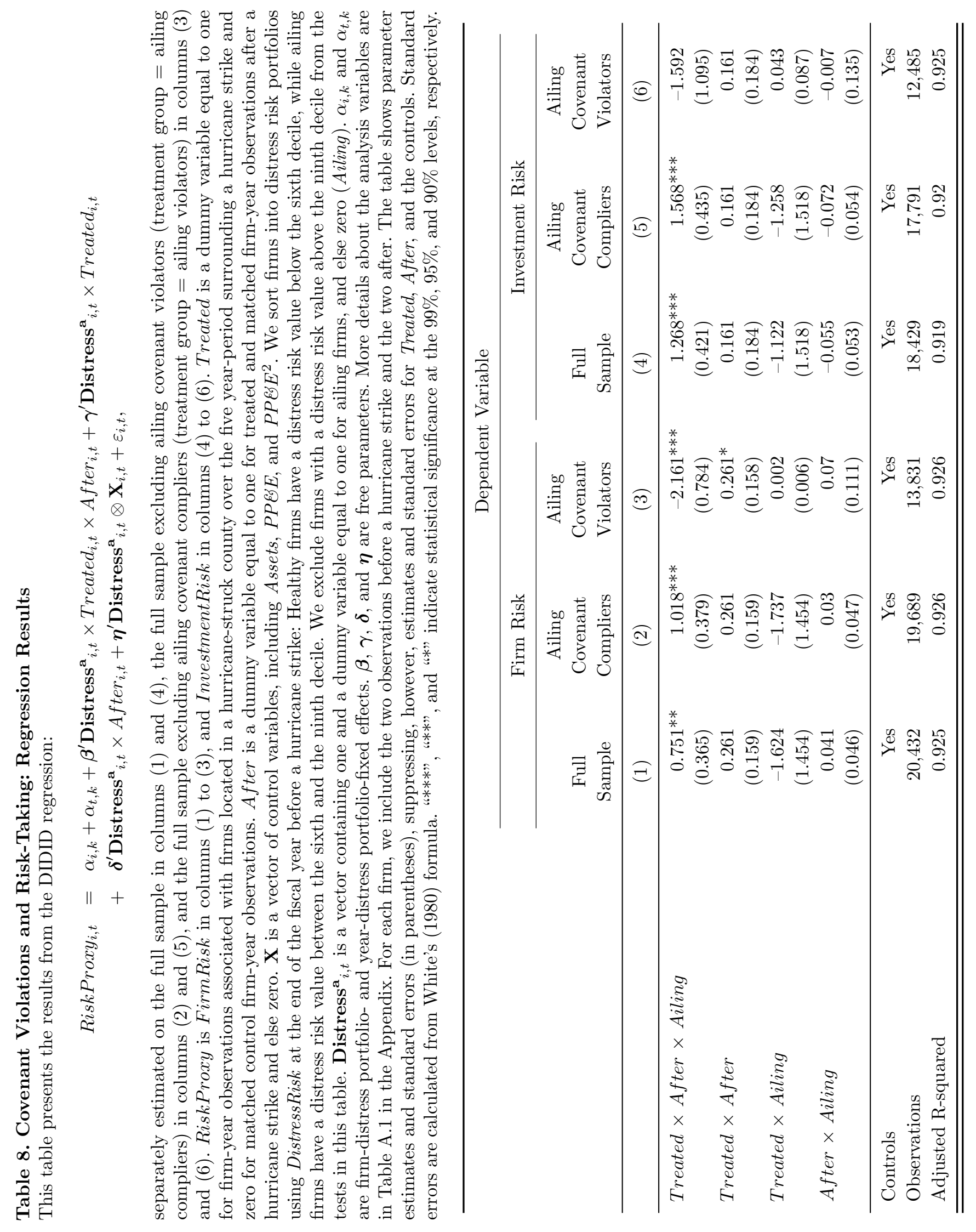




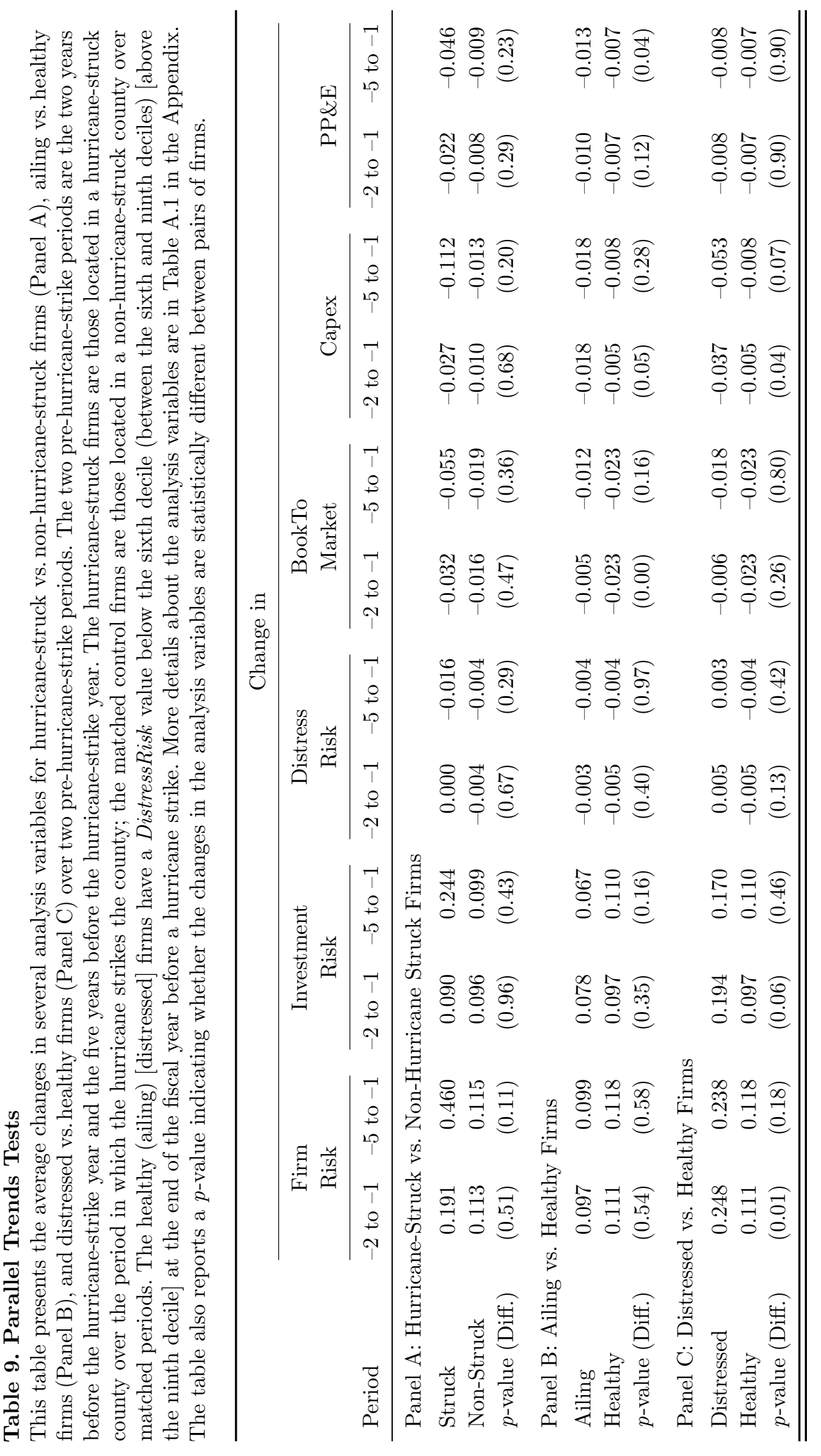


Table 10. Robustness Tests: Regression Results

This table presents the results from the DIDID regression:

$$
\begin{aligned}
\text { RiskProxy }_{i, t}^{\text {alt }} & =\alpha_{i, k}+\alpha_{t, k}+\boldsymbol{\beta}^{\prime} \text { Distress }_{i, t} \times \text { Treated }_{i, t} \times \text { After }_{i, t}+\boldsymbol{\gamma}^{\prime} \text { Distress }_{i, t} \times \text { Treated }_{i, t} \\
& +\boldsymbol{\delta}^{\prime} \text { Distress }_{i, t} \times \text { After }_{i, t}+\boldsymbol{\eta}^{\prime} \text { Distress }_{i, t} \otimes \mathbf{X}_{i, t}+\varepsilon_{i, t},
\end{aligned}
$$

where RiskProxy ${ }^{\text {alt }}$ is an alternatively calculated version of FirmRisk or InvestmentRisk. Sales-weighted firm risk is identical to FirmRisk, except that we use a segment's sales as weight. The delevered risk proxies are identical to the original ones, except that we calculate the variance-covariance matrix of the segments from delevered pure-play firm returns. The no diversification risk proxies are identical to the original ones, except that we calculate the volatilities of the pure-play firm industry portfolios as value-weighted averages of firm volatilities. Treated is a dummy variable equal to one for firm-year observations associated with firms located in a hurricane-struck county over the five year-period surrounding a hurricane strike and zero for matched control firm-year observations. After is a dummy variable equal to one for treated and matched firm-year observations after a hurricane strike and else zero. $\mathbf{X}$ is a vector of control variables, including Assets, $P P \mathscr{E} E$, and $P P \mathscr{E} E^{2}$. We sort firms into distress risk portfolios using DistressRisk at the end of the fiscal year before a hurricane strike: Healthy firms have a distress risk value below the sixth decile; ailing firms have a distress risk value between the sixth and the ninth decile; and distressed firms have a distress risk value above the ninth decile. Distress ${ }_{i, t}$ is a vector containing one, a dummy variable equal to one for ailing firms and else zero (Ailing), and a dummy variable equal to one for distressed firms and else zero (Distressed). $\alpha_{i, k}$ and $\alpha_{t, k}$ are firm-distress portfolio- and year-distress portfolio-fixed effects. $\boldsymbol{\beta}, \boldsymbol{\gamma}, \boldsymbol{\delta}$, and $\boldsymbol{\eta}$ are free parameters. More details about the analysis variables are in Table A.1 in the Appendix. For each firm, we include the two observations before a hurricane strike and the two after. The table shows parameter estimates and standard errors (in parentheses), suppressing, however, estimates and standard errors for the control variables in X. Standard errors are calculated from White's (1980) formula. "***”, “**”, and

\begin{tabular}{|c|c|c|c|c|c|}
\hline & $\begin{array}{c}\text { Sales } \\
\text { Weighted } \\
\text { Firm } \\
\text { Risk }\end{array}$ & $\begin{array}{l}\text { Delevered } \\
\text { Firm Risk }\end{array}$ & $\begin{array}{c}\text { Delevered } \\
\text { Investment } \\
\text { Risk }\end{array}$ & $\begin{array}{c}\text { No Pure-Play } \\
\text { Diversification } \\
\text { Firm Risk }\end{array}$ & $\begin{array}{c}\text { No Pure-Play } \\
\text { Diversification } \\
\text { Investment } \\
\text { Risk }\end{array}$ \\
\hline & (1) & $(2)$ & (3) & (4) & $(5)$ \\
\hline Treated $\times$ After $\times$ Ailing & $\begin{array}{l}1.055^{\text {*** }} \\
(0.375)\end{array}$ & $\begin{array}{c}0.619^{*} \\
(0.317)\end{array}$ & $\begin{array}{c}0.784^{* *} \\
(0.369)\end{array}$ & $\begin{array}{c}0.885^{*} \\
(0.452)\end{array}$ & $\begin{array}{l}1.319^{* *} \\
(0.555)\end{array}$ \\
\hline Treated $\times$ After $\times$ Distressed & $\begin{array}{l}-1.122^{* *} \\
(0.507)\end{array}$ & $\begin{array}{l}-1.309^{* * *} \\
(0.488)\end{array}$ & $\begin{array}{l}-0.963^{* *} \\
(0.414)\end{array}$ & $\begin{array}{l}-1.824^{* *} \\
(0.823)\end{array}$ & $\begin{array}{c}-1.424 \\
(1.013)\end{array}$ \\
\hline Treated $\times$ After & $\begin{array}{r}-0.211 \\
(0.303)\end{array}$ & $\begin{array}{l}-0.480^{*} \\
(0.264)\end{array}$ & $\begin{array}{l}-0.459 \\
(0.281)\end{array}$ & $\begin{array}{r}0.231 \\
(0.221)\end{array}$ & $\begin{array}{l}-0.075 \\
(0.251)\end{array}$ \\
\hline Treated $\times$ Ailing & $\begin{array}{l}-0.073^{* *} \\
(0.029)\end{array}$ & $\begin{array}{l}-0.016 \\
(0.025)\end{array}$ & $\begin{array}{l}-0.000 \\
(0.027)\end{array}$ & $\begin{array}{l}-2.979^{* * *} \\
(1.202)\end{array}$ & $\begin{array}{l}-3.709^{* * *} \\
(1.336)\end{array}$ \\
\hline Treated $\times$ Distressed & $\begin{array}{r}0.012 \\
(0.142)\end{array}$ & $\begin{array}{r}0.231 \\
(0.153)\end{array}$ & $\begin{array}{r}0.138 \\
(0.191)\end{array}$ & $\begin{array}{l}-0.845 \\
(1.694)\end{array}$ & $\begin{array}{r}0.501 \\
(3.081)\end{array}$ \\
\hline After $\times$ Ailing & $\begin{array}{l}-1.475^{*} \\
(0.798)\end{array}$ & $\begin{array}{l}-0.996 \\
(0.713)\end{array}$ & $\begin{array}{l}-2.155^{* * *} \\
(0.808)\end{array}$ & $\begin{array}{r}0.060 \\
(0.084)\end{array}$ & $\begin{array}{r}0.042 \\
(0.095)\end{array}$ \\
\hline After $\times$ Distressed & $\begin{array}{l}-2.567 \\
(1.600)\end{array}$ & $\begin{array}{r}0.895 \\
(1.055)\end{array}$ & $\begin{array}{l}-1.784^{* *} \\
(0.848)\end{array}$ & $\begin{array}{l}1.150^{* * *} \\
(0.387)\end{array}$ & $\begin{array}{l}1.222^{* * *} \\
(0.410)\end{array}$ \\
\hline Treated & $\begin{array}{c}0.101^{*} \\
(0.054)\end{array}$ & $\begin{array}{l}-0.006 \\
(0.044)\end{array}$ & $\begin{array}{r}0.020 \\
(0.050)\end{array}$ & $\begin{array}{l}-0.566 \\
(0.468)\end{array}$ & $\begin{array}{l}-0.612 \\
(0.507)\end{array}$ \\
\hline After & $\begin{array}{c}0.959^{\text {*** }} \\
(0.243)\end{array}$ & $\begin{array}{l}0.661^{* * *} \\
(0.206)\end{array}$ & $\begin{array}{c}0.687^{* * *} \\
(0.216)\end{array}$ & $\begin{array}{l}-0.077 \\
(0.048)\end{array}$ & $\begin{array}{l}-0.065 \\
(0.049)\end{array}$ \\
\hline Controls & Yes & Yes & Yes & Yes & Yes \\
\hline Observations & 27,387 & 29,209 & 26,813 & 27,387 & 25,196 \\
\hline Adjusted R-squared & 0.899 & 0.876 & 0.863 & 0.900 & 0.893 \\
\hline
\end{tabular}
“*” indicate statistical significance at the $99 \%, 95 \%$, and $90 \%$ levels, respectively. 


\title{
Internet Appendix: \\ In the Path of the Storm: \\ Does Distress Risk Cause Industrial \\ Firms to Risk-Shift?
}

\author{
Kevin Aretz, Shantanu Banerjee, and Oksana Pryshchepa
}

In this Internet Appendix, we offer supplementary results for our paper "In the Path of the Storm: Does Distress Risk Cause Industrial Firms to Risk-Shift." In Section IA.1, we use alternative distress risk breakpoints to classify firms as healthy, ailing, and distressed and reestimate our DIDID regressions explaining FirmRisk and InvestmentRisk (see Section 5.3.b and Table 4 in our main paper). In Section IA.2, we use a propensityscore (PS) matched sample to reestimate our DIDID regressions explaining how the ailing firms raise their risk (see Section 5.3.c and Table 6 in our main paper); our DIDID regressions explaining the average- $Q$ variables (see Section 5.3.d and Table 7); and our DIDID regressions using either ailing covenant-compliers or -violators as treatment group (see Section 5.3.d and Table 8). In Section IA.3, we offer the results from correlation tests and Friedman (1937) tests checking whether hurricane strikes systematically distort the volatilities of single-segment firm industry portfolios. In Section IA.4, we reestimate our DIDID regressions explaining FirmRisk and InvestmentRisk (see Section 5.3.b and Table 4 in our main paper) on a subsample of firms unlikely to have taken out insurance against the losses arising from hurricane strikes. In Section IA.5, we offer more background information about the three companies used in the FirmRisk and InvestmentRisk proxy examples (see Section 5.1 in our main paper).

\section{IA.1 Using Alternative Distress Risk Breakpoints}

Table IA.1 offers the results from reestimating DIDID regression (6) in our main paper on FirmRisk in columns (1) to (3) and InvestmentRisk in columns (4) to (6) using alternative distress risk breakpoints to classify firms as healthy, ailing, or distressed. We reestimate the regression using the alternative breakpoints since our choice of breakpoints used in our main paper is admittedly ad-hoc, and since there may be concern that the ailing firms as defined in our paper are perhaps not ailing enough to have an incentive to substitute safer for riskier assets. Defining firms with a distress risk value 
below the lower breakpoint as healthy, firms with a value between the two breakpoints as ailing, and those with a value above the higher breakpoint as distressed, we use the fifth and the ninth deciles as breakpoints in Panel A, the sixth and the ninth in Panel B, the seventh and the ninth in Panel $C$, the eighth and the ninth in Panel $D$, and the sixth and the eighth in Panel $\mathrm{E}$. Thus, the breakpoints used in Panel $\mathrm{B}$ are identical to those used in our main paper. To conserve space, Table IA.1 only reports the estimates on the triple interactions between Treated, After, and Ailing and Treated, After, and Distressed, and the double interaction between Treated and After.

Table IA.1 suggests that our evidence that ailing firms raise their risk in response to a hurricane strike is robust with respect to variations in the distress risk breakpoints used to classify firms as healthy, ailing, or distressed. In particular, the coefficients on the triple interactions involving Ailing are consistently positive and highly significant independent of the distress risk breakpoints chosen. Interestingly, however, the coefficients increase in magnitude as the ailing firms become more ailing. For example, using the sixth and ninth distress risk breakpoints to define the ailing firms (as we do in our main paper), the coefficient on the triple interaction involving Ailing is 0.861 in the model explaining FirmRisk ( $p$-value: 0.018; see Panel B). Using the eighth and the ninth deciles instead, the coefficient is 1.781 ( $p$-value: 0.000 ; see Panel $D$ ). Thus, it is the more ailing firms that are responsible for our evidence that hurricane strikes prompt ailing firms to take on more risk. Conversely, the coefficients on the triple interactions involving Distressed are only significant in the models explaining FirmRisk and only when the distressed firms are sufficiently distressed (see Panel E).

\section{IA.2 Using a PS-Matched Sample to Estimate our DIDID Regressions}

In Tables IA.2 to IA.4, we reestimate the DIDID regressions explaining how ailing firms raise their risk in response to a hurricane strike; whether the risk-taking is facilitated through good or bad investments; and whether financial covenant violations condition the risk-taking, on the PS-matched sample also used in the DIDID estimations explaining FirmRisk and InvestmentRisk in Section 5.3.b and Table 5 in our main paper. We rerun the regressions on the PS-matched sample since there may be concern that healthy and distressed firms differ along dimensions other than their distress risk, possibly biasing our results. As we explain in Section 3.2 of our main paper, we construct the PS-matched sample by estimating a logit model explaining a dummy variable equal to one if a firm has a DistressRisk value above the sixth decile and else zero, on Size, Age, and PP\&E. See Table A.1 in the Appendix of our main paper for the definitions of the covariates used in the logit model. We estimate the logit model separately by onedigit SIC code industry using only data from the year before the hurricane-strike year. We match each above-sixth-decile DistressRisk firm with one other firm belonging to the same one-digit SIC code industry and having the closest fitted value. 
Tables IA.2 to IA.4 show that the inferences derived from estimating the DIDID regression models on the PS-matched sample are almost identical to those derived from estimating the regressions on the full sample. In particular, Table IA.2 still suggests that the ailing hurricane-struck firms raise their risk in response to a hurricane strike by reorienting themselves towards higher-risk segments, while the distressed firms lower their risk in that situation by reorienting themselves towards lower-risk segments. Conversely, Table IA.3 still suggests that the ailing firms make bad investments into low average- $Q$ segments to raise their risk, while the distressed firms make good investments into high average- $Q$ segments to lower theirs. Finally, Table IA.4 still suggests that only those ailing firms still complying with their financial covenants raise their risk, while those that have violated covenants in the recent past lower theirs.

Two small deviations between the results obtained from the full sample and those obtained from the PS-matched sample are: (i) the PS-matched, but not the full, sample suggests that the distressed firms also significantly increase their capital expenditures to change their business orientation (see column (1) in Table IA.2). (ii) The full, but not the PS-matched, sample suggests that the ailing covenant violators significantly decrease their FirmRisk after a hurricane strike (see column (3) in Table IA.4).

\section{IA.3 Studying the Effects of Hurricanes on the Volatilities of Pure-Play Firms}

In Table IA.5, we study the effect of hurricane strikes on the volatilities of pure-play firm industry portfolios. We do so because our evidence would only spuriously suggest that ailing firms take on more risk after a hurricane strike if, for example, hurricane strikes lowered the risk of high-risk industries, but raised the risk of low-risk industries. To this end, we sort all firms located in hurricane-struck counties over a hurricane's event period and exclusively operating in one single two-digit SIC code industry into two-digit SIC code industries. We require that each portfolio contains a minimum of three firms starting from two years before the hurricane-strike year to two years after. We sort the firms not fulfilling this requirement into one-digit SIC code industries, again requiring that each portfolio contains a minimum of three firms over the two years before the hurricane-strike year and the two years after. We next calculate value-weighted weekly portfolio returns, from end of Wednesday of the prior week to end of Wednesday of the current week. We finally calculate the return volatilities of the portfolios separately for the two years before each hurricane-strike year and the two years after.

The table presents the Spearman rank correlation between the pre- and post-hurricane-strike volatilities and its $p$-value separately for each hurricane-strike year allowing us to form at least eight pure-play firm industry portfolios. It also reports the Friedman (1937) test statistic investigating whether the ranking of the industry portfolios according to their volatilities changes from before to after a hurricane and its $p$-value. The table shows that, for the vast majority of hurricane-strike years, the correlation between pre- and post-hurricane-strike volatilities is in excess of 0.50 , with the mean correlation 
being 0.55 and only two correlations being only insignificantly different from zero at the 90\% confidence level. Further, the Friedman (1937) test consistently rejects the hypothesis that the ranking of the industry portfolios according to their volatilities changes from before to after a hurricane strike at the $95 \%$ confidence level. While not shown, visual inspections of graphs plotting post-hurricane-strike volatilities against pre-hurricane-strike volatilities also suggest that hurricane strikes do not systematically distort the volatilities of pure-play firm industry portfolios. Overall, we thus conclude that it is unlikely that systematic effects of hurricane strikes on the volatilities of pure-play firm industry portfolios bias the results reported in our main paper. ${ }^{1}$

\section{IA.4 Rerunning the Main DIDID Regressions on Uninsured Firms}

We finally offer evidence suggesting that our result that hurricane strikes prompt ailing, but not distressed, firms to raise their risk continues to hold for the subsample of firms that are unlikely to have taken out insurance against hurricane strikes. To this end, we split the hurricane-struck firms into those that never received a positive settlement payment (Compustat item: setp) over the two- or ten-year period after a hurricane strike and those that received at least one. Settlement payments are composed of:

1. Insurance recovery and proceeds;

2. Provisions to boost reserves for litigation and settlements;

3. Reversal of reserve for litigation/settlements.

Given that settlement payments include non-insurance-related payments, it is not safe to conclude that firms that received positive settlement payments were insured against hurricane strikes, especially not if we look for such payments over the longer ten-year period. In contrast, it seems reasonably safe to conclude that firms that never received positive settlement payments were uninsured against hurricane strikes, again especially if we look for such payments over the longer ten-year period.

In Table IA.6, we report the results from rerunning our main DIDID regression (6) explaining FirmRisk and InvestmentRisk separately for firms that never received a positive settlement payment after a hurricane strike (Panel $A$ ) and for those that received at least one (Panel B). To conserve space, the table only reports the estimates on the triple interactions between Treated, After, and Ailing and Treated, After, and Distressed, and the double interaction between Treated and After. Independent of whether we consider settlement payments over the two- or ten-year period after a hurricane

\footnotetext{
${ }^{1}$ Since a similar concern applies to the segment-Q analysis in Table 7 of our main paper, we have also repeated the above correlation tests and Friedman (1937) tests using the value-weighted Qs of the pureplay firm industry portfolios, and not their volatilities. These tests also suggest that hurricane strikes do not systematically distort the ranking of the industries according to their average Qs. For example, the average Spearman rank correlation is about 0.60 in that case.
} 
strike, Panel A suggests that only using hurricane-struck firms that never received a positive settlement payment (i.e., firms unlikely to be insured against hurricane strikes) yields results consistent with those found in our main tests. More specifically, this subsample also produces evidence that hurricane strikes prompt ailing, but not distressed, firms to raise their risk. In contrast, Panel B suggests that the subsample of firms that received at least one positive settlement payment over the two-year period after a hurricane strike does not produce evidence that ailing or distressed firms raise their risk after a hurricane strike. Only when we consider settlement payments over the longer ten-year period (and thus increase the risk of including uninsured firms) does this subsample also suggest that ailing firms raise their risk after a hurricane strike.

\section{IA.5 Background Information on the Companies in the Risk Proxy Examples}

In this section, we offer more background details about the three companies (excluding Halliburton) mentioned in the FirmRisk and InvestmentRisk proxy examples in Section 5.1 in the main paper, also describing what happened to the companies next.

\section{Cincinnati Bell (1999)}

Cincinnati Bell Inc., a large telephone and communications company, consisted mainly of mature local telephone businesses up until 1999. During that period, the company was largely shielded from competition and produced healthy profits. Starting from 1999, however, it, however, faced more severe competition due to deregulation and a growing demand for new communications technologies (e.g., the internet). It responded to these threats by restructuring itself into a national provider of voice and data communications, adding two new segments to its three existing ones and increasing its risk. Over the following years, the company continued to respond to more intense competition by consolidating its operations. It integrated its businesses into four segments in 2000 and into three segments in 2001-2003. Despite that, further changes in its business environment led to a significant worsening of the company's financial health until the end of our sample period (2011).

\section{Scott Technologies $(1993,1994)$}

Scott Technologies, a diversified goods manufacturer and provider of services for consumers and industrial customers, experienced a deterioration in its profitability from 1992 onwards, with it reporting its first operating loss in 30 years in 1994. In 1992, the company initiated a major turnaround program to respond to its financial difficulties. During the turnaround program, it engaged in several important acquisitions and divestures. More specifically, the company replaced two existing businesses with two new ones, leading to a decrease in its risk. In 1994, the company continued its turnaround plan, rebranding itself as a manufacturer of medical instruments and equipment, divesting unrelated businesses, and realigning the remaining ones with its new focus. As a result, it closed all five of its existing segments and replaced them with three new ones 
in the pursued business, leading to an increase in its risk. Over the next years, the company continued streamlining its operations. In 1998, it refocused itself into one segment, leading to a further increase in risk, but ultimately restoring its financial health. In 2000, the company was acquired by Tyco International Ltd.

\section{Ralph Lauren (2004)}

Ralph Lauren Corporation, a healthy consumer goods company, operated in the same three segments over our sample period. In the early 2000s, it started responding to strong growth in its retail business and changing consumer demands by refocusing itself on its core businesses through operational restructurings and acquisitions. The refocusing, however, only led to a rebalancing of its business portfolio, and not a change of the identity of the businesses in the portfolio. The company continued its strategy of refocusing itself on its core businesses over the following years, spurring further increases in its risk. Despite that, the company remained financially healthy. 


\section{Table IA.1}

\section{The Effect of Distress Risk on Risk-Taking: Regression Results using Alternative Distress Risk Breakpoints to Classify Firms as Healthy, Ailing, or Distressed}

This table presents the results from DIDID regression (6) in our main paper, where the dependent variable is FirmRisk in columns (1) to (3) and InvestmentRisk in columns (4) to (6). Treated is a dummy variable equal to one for firm-year observations associated with firms located in a hurricane-struck county over the five year-period surrounding a hurricane strike and zero for matched control firm-year observations. After is a dummy variable equal to one for treated and matched firm-year observations after a hurricane strike and else zero. We sort firms into distress risk portfolios using DistressRisk at the end of the fiscal year before a hurricane strike: Healthy firms have a distress risk value below the fifth, sixth, seventh, and eighth decile in Panels $A, B+E, C$, and $D$, respectively. Ailing firms have a distress risk value above the fifth, sixth, seventh, and eighth deciles in Panels $A, B+E, C$, and $D$, respectively, and below the eighth and ninth deciles in Panels $E$ and $A-D$, respectively. Distressed firms have a distress risk value above the eighth and ninth deciles in Panels $E$ and $A-D$, respectively. Ailing is a dummy variable equal to one for ailing firms and else zero, while Distressed is a dummy variable equal to one for distressed firms and else zero. The control variables include Assets, PP\&E, and PP\&E-squared. The regression includes firm-distress portfolio- and year-distress portfolio-fixed effects. More details about the analysis variables are in Table A.1 in the Appendix of our main paper. The table shows parameter estimates and standard errors (in parentheses) for the treated-after interaction and the two triple interactions; other estimates are suppressed. Standard errors are calculated from White's (1980) formula. "***", "**”, and "*” indicate statistical significance at the 99\%, 95\%, and 90\% levels, respectively.

\begin{tabular}{|c|c|c|c|c|c|c|}
\hline & \multicolumn{6}{|c|}{ Dependent Variable } \\
\hline & \multicolumn{3}{|c|}{ Firm Risk } & \multicolumn{3}{|c|}{ Investment Risk } \\
\hline & \multicolumn{6}{|c|}{ Independent Variable Interacted With } \\
\hline & One & $\begin{array}{l}\text { Ailing } \\
\text { Dummy }\end{array}$ & $\begin{array}{c}\text { Distressed } \\
\text { Dummy }\end{array}$ & One & $\begin{array}{c}\text { Ailing } \\
\text { Dummy }\end{array}$ & $\begin{array}{c}\text { Distressed } \\
\text { Dummy }\end{array}$ \\
\hline & $(1)$ & $(2)$ & $(3)$ & $(4)$ & $(5)$ & (6) \\
\hline \multicolumn{7}{|c|}{ Panel A: Healthy Below Fifth Decile; Ailing Between Fifth and Ninth Deciles; Distressed Above Ninth Decile } \\
\hline \multirow[t]{2}{*}{ Treated $x$ After } & -0.003 & $0.767^{\star *}$ & $-1.039^{*}$ & -0.252 & $1.274^{\star \star *}$ & -0.393 \\
\hline & $(0.170)$ & $(0.307)$ & $(0.554)$ & $(0.205)$ & $(0.347)$ & $(0.692)$ \\
\hline \multicolumn{7}{|c|}{ Panel B: Healthy Below Sixth Decile; Ailing Between Sixth and Ninth Deciles; Distressed Above Ninth Decile } \\
\hline \multirow[t]{2}{*}{ Treated $x$ After } & 0.084 & $0.861^{* *}$ & $-1.127^{\star *}$ & -0.062 & $1.243^{\star * *}$ & -0.583 \\
\hline & $(0.151)$ & $(0.365)$ & $(0.548)$ & $(0.184)$ & $(0.410)$ & $(0.686)$ \\
\hline \multicolumn{7}{|c|}{ Panel C: Healthy Below Seventh Decile; Ailing Between Seventh and Ninth Deciles; Distressed Above Ninth Decile } \\
\hline \multirow[t]{2}{*}{ Treated $x$ After } & 0.001 & $1.401^{* * *}$ & $-1.044^{*}$ & -0.102 & $1.772^{\star \star \star}$ & -0.543 \\
\hline & $(0.164)$ & $(0.384)$ & $(0.552)$ & $(0.191)$ & $(0.437)$ & $(0.688)$ \\
\hline \multicolumn{7}{|c|}{ Panel D: Healthy Below Eighth Decile; Ailing Between Eighth and Ninth Deciles; Distressed Above Ninth Decile } \\
\hline \multirow[t]{2}{*}{ Treated $x$ After } & 0.061 & $1.781^{* * *}$ & $-1.103^{\star \star}$ & -0.045 & $2.251^{\star \star \star}$ & -0.600 \\
\hline & $(0.150)$ & $(0.496)$ & $(0.548)$ & $(0.176)$ & $(0.545)$ & $(0.684)$ \\
\hline \multicolumn{7}{|c|}{ Panel E: Healthy Below Sixth Decile; Ailing Between Sixth and Eighth Deciles; Distressed Above Eighth Decile } \\
\hline \multirow[t]{2}{*}{ Treated $x$ After } & 0.005 & $1.284^{* * *}$ & 0.422 & -0.102 & $1.554^{\star * *}$ & 0.884 \\
\hline & $(0.164)$ & $(0.470)$ & $(0.436)$ & (0.191) & $(0.499)$ & $(0.543)$ \\
\hline
\end{tabular}




\section{Table IA.2}

\section{Risk-Taking Channels: PS-Matched Regression Results}

This table presents the results from DIDID regression (6) in our main paper. The dependent variable is either Capex, Focus, NumberSegments, Cash, or AcquisitionExpense. Capex is capital expenditures scaled by total assets. Focus is a dummy variable equal to one if a firm's maximum-sales segment changes its two-digit SIC code over the current fiscal year, else zero. NumberSegments is the number of segments owned by a firm. Cash is cash and equivalents scaled by total assets. AcquisitionExpense is acquisition expenditures scaled by total assets. Treated is a dummy variable equal to one for firm-year observations associated with firms located in a hurricane-struck county over the five year-period surrounding a hurricane strike and zero for matched control firm-year observations. After is a dummy variable equal to one for treated and matched firm-year observations after a hurricane strike and else zero. We sort firms into distress risk portfolios using DistressRisk at the end of the fiscal year before a hurricane strike: Healthy firms have a distress risk value below the sixth decile. Ailing firms have a distress risk value above the sixth and below the ninth decile. Distressed firms have a distress risk value above the ninth decile. Ailing is a dummy variable equal to one for ailing firms and else zero, while Distressed is a dummy variable equal to one for distressed firms and else zero. The control variables include Assets, $P P \& E$, and PP\&E-squared. The regression includes firm-distress portfolio- and year-distress portfoliofixed effects. More details about the analysis variables are in Table A.1 in the Appendix of our main paper. We estimate the regressions on a propensity-score (PS) matched sample. To do so, we use a logit model to estimate the probability that a firm has a DistressRisk value above the sixth decile, using Assets, Age, and PP\&E as covariates. The logit model is estimated separately by one-digit SIC code industry, using only data from the fiscal year before a hurricane strike. We next match each firm with a DistressRisk value above the sixth decile with that below-sixth-decile value firm with the closest fitted value and from the same one-digit SIC code industry. The table shows parameter estimates and standard errors (in parentheses), suppressing, however, estimates and standard errors for the control variables. Standard errors are calculated from White's (1980) formula. "***”, " “*”, and "*” indicate statistical significance at the $99 \%, 95 \%$, and $90 \%$ levels, respectively.

\begin{tabular}{|c|c|c|c|c|c|}
\hline & Capex & Focus & $\begin{array}{l}\text { Number } \\
\text { Segments }\end{array}$ & Cash & $\begin{array}{c}\text { Acquisition } \\
\text { Expense }\end{array}$ \\
\hline & $(1)$ & (2) & (3) & (4) & (5) \\
\hline Treated $x$ After $\times$ Ailing & $\begin{array}{c}0.056^{* * *} \\
(0.021)\end{array}$ & $\begin{array}{l}0.086^{\star *} \\
(0.042)\end{array}$ & $\begin{array}{c}-0.297^{* * *} \\
(0.107)\end{array}$ & $\begin{array}{l}-0.016 \\
(0.028)\end{array}$ & $\begin{array}{l}-0.014 \\
(0.022)\end{array}$ \\
\hline Treated $\times$ After $\times$ Distressed & $\begin{array}{l}0.038^{\star} \\
(0.020)\end{array}$ & $\begin{array}{c}0.266^{* * *} \\
(0.088)\end{array}$ & $\begin{array}{l}-0.159 \\
(0.116)\end{array}$ & $\begin{array}{c}-0.066^{* * *} \\
(0.025)\end{array}$ & $\begin{array}{l}-0.030 \\
(0.020)\end{array}$ \\
\hline Treated $x$ After & $\begin{array}{l}-0.044^{* *} \\
(0.019)\end{array}$ & $\begin{array}{l}-0.023 \\
(0.031)\end{array}$ & $\begin{array}{l}0.155^{*} \\
(0.086)\end{array}$ & $\begin{array}{c}0.007 \\
(0.019)\end{array}$ & $\begin{array}{c}0.023 \\
(0.019)\end{array}$ \\
\hline Treated $x$ Ailing & $\begin{array}{l}-0.074^{* *} \\
(0.029)\end{array}$ & $\begin{array}{l}-0.018 \\
(0.041)\end{array}$ & $\begin{array}{c}0.151 \\
(0.172)\end{array}$ & $\begin{array}{l}-0.010 \\
(0.036)\end{array}$ & $\begin{array}{c}0.105^{\star \star \star} \\
(0.035)\end{array}$ \\
\hline Treated $x$ Distressed & $\begin{array}{l}-0.030 \\
(0.028)\end{array}$ & $\begin{array}{c}0.059 \\
(0.320)\end{array}$ & $\begin{array}{c}-0.637^{\star *} \\
(0.301)\end{array}$ & $\begin{array}{c}0.076 \\
(0.048)\end{array}$ & $\begin{array}{c}0.054 \\
(0.054)\end{array}$ \\
\hline After $\times$ Ailing & $\begin{array}{c}0.001 \\
(0.002)\end{array}$ & $\begin{array}{c}0.000 \\
(0.008)\end{array}$ & $\begin{array}{l}-0.000 \\
(0.021)\end{array}$ & $\begin{array}{c}0.022^{\star \star *} \\
(0.006)\end{array}$ & $\begin{array}{c}-0.010^{\star * *} \\
(0.004)\end{array}$ \\
\hline After $\times$ Distressed & $\begin{array}{l}0.008^{* *} \\
(0.004)\end{array}$ & $\begin{array}{c}0.021 \\
(0.016)\end{array}$ & $\begin{array}{l}-0.060^{*} \\
(0.032)\end{array}$ & $\begin{array}{l}0.024^{* *} \\
(0.010)\end{array}$ & $\begin{array}{c}-0.016^{* * *} \\
(0.005)\end{array}$ \\
\hline Treated & $\begin{array}{c}0.038 \\
(0.025)\end{array}$ & $\begin{array}{c}0.013 \\
(0.022)\end{array}$ & $\begin{array}{l}-0.213 \\
(0.133)\end{array}$ & $\begin{array}{l}0.058^{\star *} \\
(0.027)\end{array}$ & $\begin{array}{l}-0.049^{\star} \\
(0.026)\end{array}$ \\
\hline After & $\begin{array}{l}-0.003^{*} \\
(0.001)\end{array}$ & $\begin{array}{c}0.000 \\
(0.006)\end{array}$ & $\begin{array}{c}0.013 \\
(0.017)\end{array}$ & $\begin{array}{l}-0.011^{* *} \\
(0.005)\end{array}$ & $\begin{array}{l}0.007^{* *} \\
(0.003)\end{array}$ \\
\hline Controls & Yes & Yes & Yes & Yes & Yes \\
\hline Observations & 14,560 & 14,054 & 14,054 & 14,050 & 14,054 \\
\hline Adjusted R-squared & 0.504 & 0.172 & 0.748 & 0.643 & 0.140 \\
\hline
\end{tabular}




\section{Table IA.3}

\section{Investment Efficiency: PS-Matched Regression Results}

This table presents the results from DIDID regression (6) in our main paper. The dependent variable is

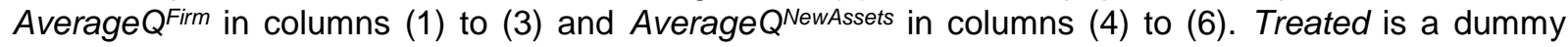
variable equal to one for firm-year observations associated with firms located in a hurricane-struck county over the five year-period surrounding a hurricane strike and zero for matched control firm-year observations. After is a dummy variable equal to one for treated and matched firm-year observations after a hurricane strike and else zero. We sort firms into distress risk portfolios using DistressRisk at the end of the fiscal year before a hurricane strike: Healthy firms have a distress risk value below the sixth decile. Ailing firms have a distress risk value above the sixth and below the ninth decile. Distressed firms have a distress risk value above the ninth decile. Ailing is a dummy variable equal to one for ailing firms and else zero, while Distressed is a dummy variable equal to one for distressed firms and else zero. The control variables include Assets, PP\&E, and PP\&E-squared. The regression includes firm-distress portfolio- and year-distress portfolio-fixed effects. More details about the analysis variables are in Table A.1 in the Appendix of our main paper. We estimate the regressions on a propensity-score (PS) matched sample. To do so, we use a logit model to estimate the probability that a firm has a DistressRisk value above the sixth decile, using Assets, Age, and PP\&E as covariates. The logit model is estimated separately by one-digit SIC code industry, using only data from the fiscal year before a hurricane strike. We match each firm with a DistressRisk value above the sixth decile with that below-sixth-decile value firm with the closest fitted value and from the same one-digit SIC code industry. The table shows parameter estimates and standard errors (in parentheses). Standard errors are calculated from White's (1980) formula. "***”, "**”, and "*” indicate statistical significance at the 99\%, 95\%, and 90\% levels, respectively.

\begin{tabular}{|c|c|c|c|c|c|c|}
\hline & \multicolumn{6}{|c|}{ Dependent Variable } \\
\hline & \multicolumn{3}{|c|}{ Average $Q^{\text {Firm }}$} & \multicolumn{3}{|c|}{ Average $Q^{\text {NewAssets }}$} \\
\hline & \multicolumn{6}{|c|}{ Independent Variable Interacted With } \\
\hline & One & $\begin{array}{c}\text { Ailing } \\
\text { Dummy }\end{array}$ & $\begin{array}{c}\text { Distressed } \\
\text { Dummy }\end{array}$ & One & $\begin{array}{c}\text { Ailing } \\
\text { Dummy }\end{array}$ & $\begin{array}{c}\text { Distressed } \\
\text { Dummy }\end{array}$ \\
\hline & $(1)$ & $(2)$ & (3) & $(4)$ & $(5)$ & (6) \\
\hline Treated $x$ After & $\begin{array}{c}0.067 \\
(0.091)\end{array}$ & $\begin{array}{c}-0.395^{\star * *} \\
(0.135)\end{array}$ & $\begin{array}{c}0.214 \\
(0.197)\end{array}$ & $\begin{array}{l}-0.030 \\
(0.108)\end{array}$ & $\begin{array}{l}-0.260^{\star} \\
(0.146)\end{array}$ & $\begin{array}{c}0.385^{*} \\
(0.210)\end{array}$ \\
\hline Treated & $\begin{array}{c}0.496^{\star * *} \\
(0.163)\end{array}$ & $\begin{array}{c}-0.471^{* *} \\
(0.195)\end{array}$ & $\begin{array}{c}0.000 \\
(0.000)\end{array}$ & $\begin{array}{c}0.511^{\star \star *} \\
(0.171)\end{array}$ & $\begin{array}{c}-0.600^{* * *} \\
(0.204)\end{array}$ & $\begin{array}{c}0.000 \\
(0.000)\end{array}$ \\
\hline After & $\begin{array}{l}-0.005 \\
(0.027)\end{array}$ & $\begin{array}{c}0.005 \\
(0.032)\end{array}$ & $\begin{array}{l}-0.000 \\
(0.056)\end{array}$ & $\begin{array}{c}0.009 \\
(0.030)\end{array}$ & $\begin{array}{c}0.001 \\
(0.036)\end{array}$ & $\begin{array}{c}0.040 \\
(0.070)\end{array}$ \\
\hline Assets & $\begin{array}{c}-0.113^{* * *} \\
(0.034)\end{array}$ & $\begin{array}{c}0.039 \\
(0.043)\end{array}$ & $\begin{array}{c}0.034 \\
(0.054)\end{array}$ & $\begin{array}{c}-0.086^{* *} \\
(0.038)\end{array}$ & $\begin{array}{c}0.045 \\
(0.048)\end{array}$ & $\begin{array}{c}0.077 \\
(0.067)\end{array}$ \\
\hline PP\&E & $\begin{array}{c}0.218 \\
(0.295)\end{array}$ & $\begin{array}{c}0.144 \\
(0.350)\end{array}$ & $\begin{array}{c}0.235 \\
(0.437)\end{array}$ & $\begin{array}{c}-0.157 \\
(0.318)\end{array}$ & $\begin{array}{c}0.361 \\
(0.377)\end{array}$ & $\begin{array}{c}0.510 \\
(0.469)\end{array}$ \\
\hline$P P \& E^{2}$ & $\begin{array}{c}0.068 \\
(0.187)\end{array}$ & $\begin{array}{l}-0.205 \\
(0.225)\end{array}$ & $\begin{array}{l}-0.307 \\
(0.286)\end{array}$ & $\begin{array}{c}0.292 \\
(0.205)\end{array}$ & $\begin{array}{l}-0.396 \\
(0.246)\end{array}$ & $\begin{array}{l}-0.488 \\
(0.309)\end{array}$ \\
\hline Observations & & 12,687 & & & 11,569 & \\
\hline Adjusted R-squared & & 0.602 & & & 0.585 & \\
\hline
\end{tabular}




\section{Table IA.4}

\section{Covenant Violations and Risk-Taking: PS-Matched Regression Results}

This table presents the results from DIDID regression (6) in our main paper, separately estimated on the full sample in columns (1) and (4), the full sample excluding ailing covenant violators (treatment group = ailing compliers) in columns (2) and (5), and the full sample excluding ailing covenant compliers (treatment group = ailing violators) in columns (3) and (6). The dependent variable is FirmRisk in columns (1) to (3) and InvestmentRisk in columns (4) to (6). Treated is a dummy variable equal to one for firm-year observations associated with firms located in a hurricane-struck county over the five year-period surrounding a hurricane strike and zero for matched control firm-year observations. After is a dummy variable equal to one for treated and matched firm-year observations after a hurricane strike and else zero. We sort firms into distress risk portfolios using DistressRisk at the end of the fiscal year before a hurricane strike: Healthy firms have a distress risk value below the sixth decile. Ailing firms have a distress risk value above the sixth and below the ninth decile. Ailing is a dummy variable equal to one for ailing firms and else zero. The analysis excludes firms with a distress risk value above the ninth decile, and thus also drops all terms involving Distressed from the regression model. The control variables include Assets, $P P \& E$, and PP\&E-squared. The regression includes firm-distress portfolio- and year-distress portfoliofixed effects. More details about the analysis variables are in Table A.1 in the Appendix of our main paper. We estimate the regressions on a propensity-score (PS) matched sample. To do so, we use a logit model to estimate the probability that a firm has a DistressRisk value above the sixth decile, using Assets, Age, and PP\&E as covariates. The logit model is estimated separately by one-digit SIC code industry, using only data from the fiscal year before a hurricane strike. We next match each firm with a DistressRisk value above the sixth decile with that below-sixth-decile value firm with the closest fitted value and from the same one-digit SIC code industry. The table shows parameter estimates and standard errors (in parentheses), suppressing, however, estimates and standard errors for Treated, After, and the controls. Standard errors are calculated from White's (1980) formula. "***”, "**”, and "** indicate statistical significance at the $99 \%, 95 \%$, and $90 \%$ levels, respectively.

\begin{tabular}{|c|c|c|c|c|c|c|}
\hline & \multicolumn{6}{|c|}{ Dependent Variable } \\
\hline & \multicolumn{3}{|c|}{ Firm Risk } & \multicolumn{3}{|c|}{ Investment Risk } \\
\hline & $\begin{array}{c}\text { Full } \\
\text { Sample }\end{array}$ & $\begin{array}{c}\text { Ailing } \\
\text { Covenant } \\
\text { Compliers }\end{array}$ & $\begin{array}{c}\text { Ailing } \\
\text { Covenant } \\
\text { Violators }\end{array}$ & $\begin{array}{c}\text { Full } \\
\text { Sample }\end{array}$ & $\begin{array}{c}\text { Ailing } \\
\text { Covenant } \\
\text { Compliers }\end{array}$ & $\begin{array}{l}\text { Ailing } \\
\text { Covenant } \\
\text { Violators }\end{array}$ \\
\hline & (1) & (2) & (3) & $(4)$ & (5) & (6) \\
\hline Treated $\times$ After $\times$ Ailing & $\begin{array}{c}1.468^{* * *} \\
(0.501)\end{array}$ & $\begin{array}{l}1.736^{\star \star *} \\
(0.528)\end{array}$ & $\begin{array}{l}-1.181 \\
(0.842)\end{array}$ & 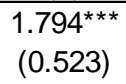 & $\begin{array}{c}2.046^{* * *} \\
(0.550)\end{array}$ & $\begin{array}{c}-0.569 \\
(1.186)\end{array}$ \\
\hline Treated $\mathrm{x}$ After & $\begin{array}{c}0.133 \\
(0.249)\end{array}$ & $\begin{array}{c}0.133 \\
(0.250)\end{array}$ & $\begin{array}{c}0.133 \\
(0.254)\end{array}$ & $\begin{array}{c}0.221 \\
(0.232)\end{array}$ & $\begin{array}{c}0.221 \\
(0.232)\end{array}$ & $\begin{array}{c}0.221 \\
(0.237)\end{array}$ \\
\hline Treated $x$ Ailing & $\begin{array}{l}-4.273 \\
(3.093)\end{array}$ & $\begin{array}{l}-4.395 \\
(3.082)\end{array}$ & $\begin{array}{c}0.002 \\
(0.006)\end{array}$ & $\begin{array}{l}-4.378 \\
(3.073)\end{array}$ & $\begin{array}{l}-4.502 \\
(3.065)\end{array}$ & $\begin{array}{c}0.043 \\
(0.087)\end{array}$ \\
\hline After $\times$ Ailing & $\begin{array}{c}0.068 \\
(0.064)\end{array}$ & $\begin{array}{c}0.065 \\
(0.065)\end{array}$ & $\begin{array}{c}0.077 \\
(0.130)\end{array}$ & $\begin{array}{l}-0.043 \\
(0.072)\end{array}$ & $\begin{array}{c}-0.052 \\
(0.074)\end{array}$ & $\begin{array}{c}0.005 \\
(0.155)\end{array}$ \\
\hline Controls & Yes & Yes & Yes & Yes & Yes & Yes \\
\hline Observations & 9,347 & 8,674 & 3,923 & 8,400 & 7,824 & 3,513 \\
\hline Adjusted R-Squared & 0.918 & 0.921 & 0.926 & 0.906 & 0.908 & 0.927 \\
\hline
\end{tabular}




\section{Table IA.5}

\section{The Effect of Hurricanes on the Volatilities of Pure-Play Firm Industry Portfolios}

This table presents the results from tests investigating the effect of hurricane strikes on the stock return volatilities of pure-play firm industry portfolios. To form the pure-play firm industry portfolios, we sort all firms located in hurricane-struck counties over a hurricane's event period and exclusively operating in one single two-digit SIC code industry into two-digit SIC code industry portfolios. We require that each portfolio contains a minimum of three firms starting from two years before the hurricane-strike year to two years after. We sort the firms not fulfilling this requirement into one-digit SIC code industry portfolios, again requiring that each portfolio contains a minimum of three firms over the two years before the hurricane-strike year and the two years after. We calculate value-weighted weekly stock returns for the portfolios, from end of Wednesday of the prior week to end of Wednesday of the current. We next calculate the stock return volatilities of the portfolios separately for the two years before each hurricane strike year and the two years after. Separately using data from hurricane seasons allowing us to form at least eight portfolios, we calculate the Spearman rank correlation between the pre- and post-hurricane volatilities and the $p$-value of the correlation (see "Correlation Before vs. After-Strike Industry Volatility"). We also calculate the Friedman (1937) test statistic analyzing whether the ranking of the pure-play firm industry portfolios according to their volatilities changes from the pre- to the post-hurricane period and the $p$-value of that test (see "Friedman Test of Equal Before and After Industry Volatility Ranks").

\begin{tabular}{|c|c|c|c|c|c|}
\hline \multirow[b]{2}{*}{$\begin{array}{l}\text { Hurricane } \\
\text { Season }\end{array}$} & \multirow[b]{2}{*}{$\begin{array}{l}\text { Number of } \\
\text { Industries }\end{array}$} & \multicolumn{2}{|c|}{$\begin{array}{c}\text { Correlation } \\
\text { Before vs. After-Strike } \\
\text { Industry Volatility }\end{array}$} & \multicolumn{2}{|c|}{$\begin{array}{c}\text { Friedman Test of } \\
\text { Equal Before and After } \\
\text { Industry Volatility Ranks }\end{array}$} \\
\hline & & Estimate & $\mathrm{p}$-value & Estimate & $\mathrm{p}$-value \\
\hline 1994 & 9 & 0.834 & $(0.01)$ & 13.73 & $(0.09)$ \\
\hline 1995 & 15 & 0.203 & $(0.47)$ & 17.45 & $(0.23)$ \\
\hline 1996 & 10 & 0.829 & $(0.00)$ & 16.04 & $(0.07)$ \\
\hline 1998 & 18 & 0.506 & $(0.03)$ & 26.53 & $(0.07)$ \\
\hline 1999 & 12 & 0.596 & $(0.05)$ & 16.91 & $(0.08)$ \\
\hline 2001 & 11 & 0.643 & $(0.03)$ & 15.82 & $(0.11)$ \\
\hline 2003 & 11 & 0.519 & $(0.10)$ & 17.00 & $(0.07)$ \\
\hline 2004 & 14 & 0.629 & $(0.02)$ & 22.29 & $(0.06)$ \\
\hline 2005 & 14 & 0.463 & $(0.10)$ & 20.40 & $(0.09)$ \\
\hline 2008 & 12 & 0.272 & $(0.39)$ & 15.23 & $(0.17)$ \\
\hline
\end{tabular}




\section{Table IA.6}

\section{Catastrophe Insurance and Risk-Taking: Regression Results}

This table presents the results from DIDID regression (6) in our main paper estimated using either noninsured (Panel A) or insured (Panel B) hurricane struck firms. We define an uninsured firm as a firm that did not receive a single positive settlement payment over the two- or ten-year periods after a hurricane strike, while we define an insured firm as a firm that received at least one such payment over the same periods. The dependent variable is FirmRisk in columns (1) to (3) and InvestmentRisk in columns (4) to (6). Treated is a dummy variable equal to one for firm-year observations associated with firms located in a hurricane-struck county over the five year-period surrounding a hurricane strike and zero for matched control firm-year observations. After is a dummy variable equal to one for treated and matched firm-year observations after a hurricane strike and else zero. We sort firms into distress risk portfolios using DistressRisk at the end of the fiscal year before a hurricane strike: Healthy firms have a distress risk value below the sixth decile. Ailing firms have a distress risk value above the sixth and below the ninth decile. Distressed firms have a distress risk value above the ninth decile. Ailing is a dummy variable equal to one for ailing firms and else zero, while Distressed is a dummy variable equal to one for distressed firms and else zero. The control variables include Assets, PP\&E, and PP\&E-squared. The regression includes firm-distress portfolio- and year-distress portfolio-fixed effects. More details about the analysis variables are in Table A.1 in the Appendix of our main paper. The table shows parameter estimates and standard errors (in parentheses) for the treated-after interaction and the two triple interactions; other estimates are suppressed. Standard errors are calculated from White's (1980) formula. “***”, "**”, and "“* indicate statistical significance at the $99 \%, 95 \%$, and $90 \%$ levels, respectively.

\begin{tabular}{|c|c|c|c|c|c|c|}
\hline & \multicolumn{6}{|c|}{ Dependent Variable } \\
\hline & \multicolumn{3}{|c|}{ Firm Risk } & \multicolumn{3}{|c|}{ Investment Risk } \\
\hline & \multicolumn{6}{|c|}{ Independent Variable Interacted With } \\
\hline & One & $\begin{array}{c}\text { Ailing } \\
\text { Dummy }\end{array}$ & $\begin{array}{c}\text { Distressed } \\
\text { Dummy }\end{array}$ & One & $\begin{array}{c}\text { Ailing } \\
\text { Dummy }\end{array}$ & $\begin{array}{c}\text { Distressed } \\
\text { Dummy }\end{array}$ \\
\hline & (1) & (2) & (3) & (4) & (5) & (6) \\
\hline \multicolumn{7}{|c|}{ Panel A: Uninsured Firms } \\
\hline \multicolumn{7}{|c|}{ No Positive Settlement Payments over the Two Years After a Hurricane Strike } \\
\hline Treated x After & $\begin{array}{c}0.015 \\
(0.173)\end{array}$ & $\begin{array}{c}1.518^{\star * *} \\
(0.422)\end{array}$ & $\begin{array}{l}-1.125^{*} \\
(0.591)\end{array}$ & $\begin{array}{l}-0.131 \\
(0.190)\end{array}$ & $\begin{array}{c}1.910^{\star \star *} \\
(0.471)\end{array}$ & $\begin{array}{l}-0.556 \\
(0.734)\end{array}$ \\
\hline \multicolumn{7}{|c|}{ No Positive Settlement Payments over the Ten Years After a Hurricane Strike } \\
\hline Treated x After & $\begin{array}{l}-0.024 \\
(0.247)\end{array}$ & $\begin{array}{c}1.409^{\star \star \star} \\
(0.457)\end{array}$ & $\begin{array}{l}-1.063 \\
(0.880)\end{array}$ & $\begin{array}{l}-0.210 \\
(0.297)\end{array}$ & $\begin{array}{l}1.716^{\star *} \\
(0.689)\end{array}$ & $\begin{array}{c}0.324 \\
(1.041)\end{array}$ \\
\hline \multicolumn{7}{|c|}{ Panel B: Insured Firms } \\
\hline \multicolumn{7}{|c|}{ At Least One Positive Settlement Payment over the Two Years After a Hurricane Strike } \\
\hline Treated $\times$ After & $\begin{array}{l}-0.117 \\
(0.462)\end{array}$ & $\begin{array}{c}0.397 \\
(0.584)\end{array}$ & $\begin{array}{l}-0.067 \\
(0.508)\end{array}$ & $\begin{array}{c}0.135 \\
(0.577)\end{array}$ & $\begin{array}{c}0.478 \\
(0.670)\end{array}$ & $\begin{array}{l}-0.278 \\
(0.634)\end{array}$ \\
\hline \multicolumn{7}{|c|}{ At Least One Positive Settlement Payment over the Ten Years After a Hurricane Strike } \\
\hline Treated x After & $\begin{array}{c}0.011 \\
(0.200)\end{array}$ & $\begin{array}{c}1.398^{* * *} \\
(0.456)\end{array}$ & $\begin{array}{c}-1.003^{* *} \\
(0.473)\end{array}$ & $\begin{array}{l}-0.066 \\
(0.223)\end{array}$ & $\begin{array}{c}1.771^{\star * *} \\
(0.502)\end{array}$ & $\begin{array}{c}-1.623^{* *} \\
(0.693)\end{array}$ \\
\hline
\end{tabular}

